\title{
Engineered Extracellular Vesicles for Cancer Therapy
}

\section{Extracellular vesicles (EVs) have emerged as a novel cell-free strategy for the} treatment of many diseases including cancer. As a result of their natural properties to mediate cell-to-cell communication and high physiochemical stability and biocompatibility, EVs have been considered as excellent delivery vehicles for a variety of therapeutic agents such as nucleic acids and proteins, drugs, and nanomaterials. Increasing studies have shown that EVs can be modified, engineered, or designed to improve their efficiency, specificity, and safety for cancer therapy. Herein, a comprehensive overview on the recent advances in the strategies and methodologies of engineering EVs for scalable production and improved cargo-loading and tumor-targeting is provided. Additionally, the potential applications of engineered EVs in cancer therapy are discussed by presenting prominent examples and the opportunities and challenges for translating engineered EVs into clinical practice are evaluated.

\section{Introduction}

Extracellular vesicles (EVs) are nano-sized vesicles secreted by all types of cells. ${ }^{[1]}$ EVs carry a variety of bioactive molecules such as nucleic acids and proteins and transfer them from donor cells to recipient cells through multiple mechanisms such as direct membrane fusion, receptor-ligand interaction, and endocytosis or phagocytosis. ${ }^{[2]}$ Increasing studies reveal that EVs mediate signal transduction and play important roles in intercellular communication, thus participating in many physiological and pathological processes. ${ }^{[3]}$ The discovery that EVs transfer bioactive molecules between cells promotes the idea of developing them as potential therapeutic agents and

Prof. X. Zhang, Dr. J. Zhang, Dr. H. Shi, Prof. H. Qian, Prof. W. Xu Jiangsu Key Laboratory of Medical Science and Laboratory Medicine School of Medicine

Jiangsu University

Zhenjiang 212013, P. R. China

E-mail: xuzhang@ujs.edu.cn

Prof. H. Zhang

Pharmaceutical Sciences Laboratory and Turku Bioscience Centre

Åbo Akademi University

Turku 20520, Finland

Prof. H. Zhang, Prof. D. Wang

Department of Radiology

Affiliated Hospital of Jiangsu University

Jiangsu University

Zhenjiang 212001, P. R. China

The ORCID identification number(s) for the author(s) of this article can be found under https://doi.org/10.1002/adma.202005709.

DOI: $10.1002 / \mathrm{adma.202005709}$

Prof. H. A. Santos
Moreover, EVs inherit targeting propertie from their producing cells, which is beneficial for the accumu- 28 lation of therapeutic cargos at local diseased sites after systemic 29 infusion. ${ }^{8]}$ Together, these unique biological features make EVs 30 one of the promising candidates for nanomedicine. ${ }^{[9]} 31$

Previous studies have shown that natural EVs from certain 32 sources, such as tumor cells and immune cells, could elicit 33 antitumor activities and have the potential to be used as cancer 34 vaccines. Further studies have employed EVs to deliver var- 35 ious therapeutic molecules and chemotherapeutic drugs and 36 achieved promising effects. ${ }^{[10,11]}$ However, the use of natural 37 EVs for cancer therapy has several problems. For instance, EVs 38 are prone to be trapped in nonspecific tissues, especially in 39 the liver and lung, leading to insufficient targeting in vivo. ${ }^{[12]} 40$

Department of Clinical Laboratory Medicine

Nantong Tumor Hospital

Nantong 226361, P. R. China

Prof. J. Pan

School of Chemistry and Chemical Engineering

Jiangsu University

Zhenjiang 212013, P. R. China

E-mail: pjm@ujs.edu.cn

Drug Research Program

Division of Pharmaceutical Chemistry and Technology 52

Faculty of Pharmacy

University of Helsinki

Helsinki FI-00014, Finland

E-mail: helder.santos@helsinki.fi

Prof. H. A. Santos

Helsinki Institute of Life Science (HiLIFE)

University of Helsinki

Helsinki FI-00014, Finland 


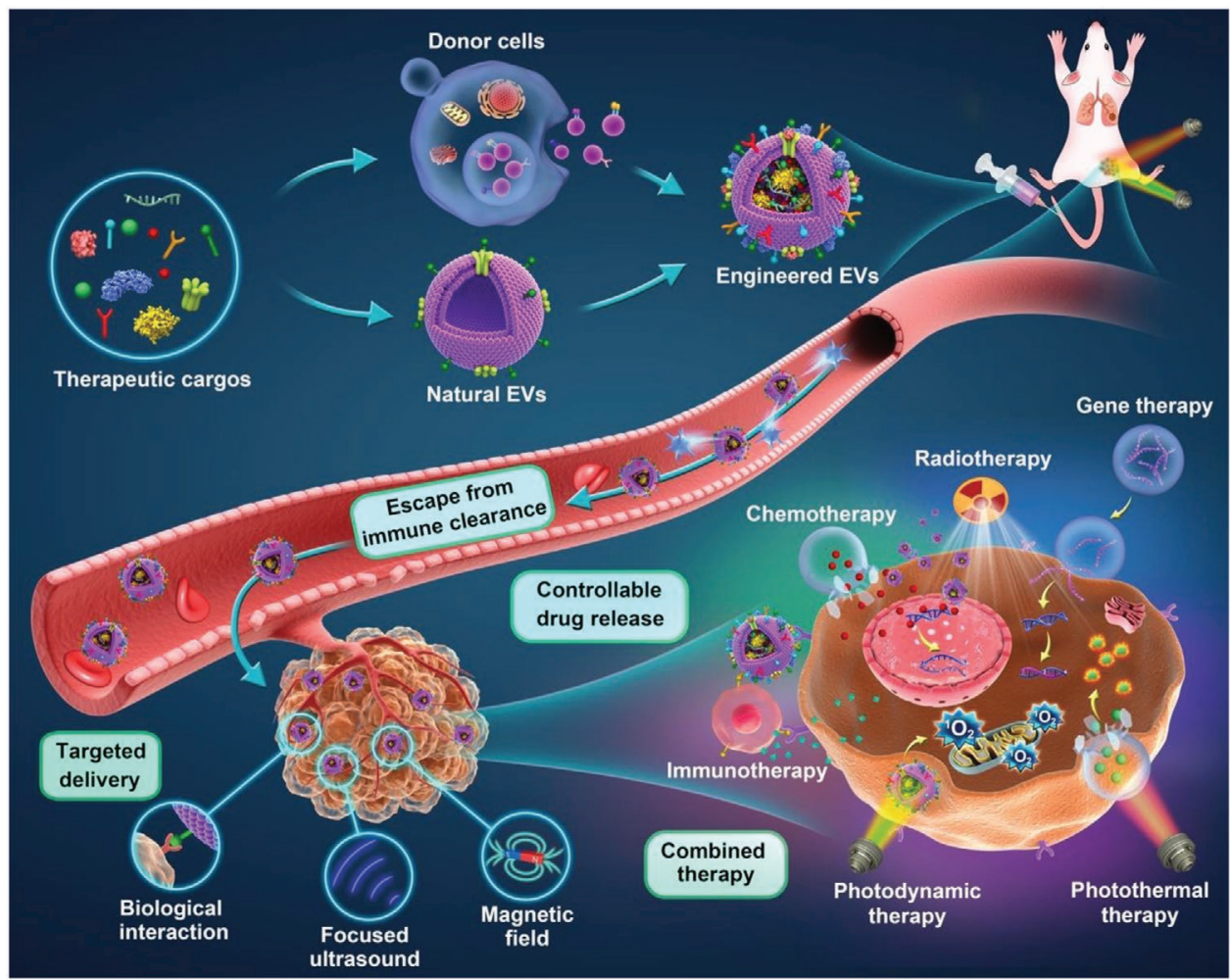

Figure 1. Engineered EVs as advanced nanomaterials for cancer therapy. Traditional and advanced bio-techniques have been used to manipulate donor cells or their derived EVs to generate engineered EVs that deliver a variety of therapeutic molecules, drugs, and nanomaterials. Engineered EVs have superior characteristics to their natural counterparts, including long circulation and high stability, tumor-targeting ability, deep penetration and enhanced accumulation, efficient intracellular delivery, and controllable drug release, which remarkably improve the specificity, efficacy, and safety of EV-based cancer therapeutics.

In addition, the heterogeneity and complicated components of EVs reduce therapeutic efficacy and bring safety concerns when they are used to deliver therapeutic cargos. Moreover, the lack of efficient isolation and scale-up production of EVs and accurate monitoring of the dosage of therapeutic cargos in EVs are also potential problems when used in the clinical settings. Thus, engineered EVs have recently emerged as a new strategy and hold great promise to be used as an alternative approach for EV-based therapy (Figure 1). ${ }^{[13]}$ Accumulating evidence suggest that the engineering of EVs enhances their loading efficiency, targeting ability, and therapeutic effect. ${ }^{[14]}$ At present, there are two main strategies for loading a desired cargo into EVs. One strategy is incorporating a cargo into the producer cells and obtaining the cargo-loaded EVs through natural biogenesis process. The other one is harvesting EVs from distinct sources (e.g., cultured cells, human blood, and milk) and introducing a cargo into EVs through traditional and advanced bio-techniques. ${ }^{[15]}$ There is also growing interest in modifying EV membranes to make them target specific tissues and combining EVs with other nanomaterials to achieve improved or synergistic therapy effects. ${ }^{[16]}$ The fabrication of bio-inspired or bio-mimetic EVs with higher production yield and loading efficiency has also been extensively explored. ${ }^{[17]}$

In this review, we summarized the recent advances in the modification, engineering, and design of EVs as nanovehicles for delivering therapeutic agents with an emphasis on their applications in cancer therapy, which will help better understand the current progress and future research directions of this field.

\section{EV Characteristics, Biogenesis, and Contents}

EVs are a heterogeneous group of membrane-structured vesicles actively released by all types of cells and are found in many human body fluids such as blood, urine, and ascites. ${ }^{[18]}$ Three main populations of EVs have been proposed according to their size and origin: exosomes, microvesicles (MVs) or microparticles (MPs), and apoptotic bodies (Figure 2). Exosomes, with a diameter of 30-150 $\mathrm{nm}$, are vesicles derived from the fusion of multivesicular bodies (MVBs) and plasma membranes, while MVs, with a size ranging from 50 to $1000 \mathrm{~nm}$, are formed as a result of direct outward budding of plasma membranes. Apoptotic bodies are released by dying cells after apoptosis. Most studies focus on the potential of exosomes and MVs/MPs in nanomedicine. There are few studies on the use of apoptotic bodies as therapeutic NVs, which may be associated with their large and uneven size. EVs are enriched in nucleic acids, proteins, lipids, metabolites, and even organelles from donor cells. Initially thought as a way for the disposal of cell waste, EVs have recently been recognized as a key player in regulating intercellular communications. The biological roles of EVs in human 

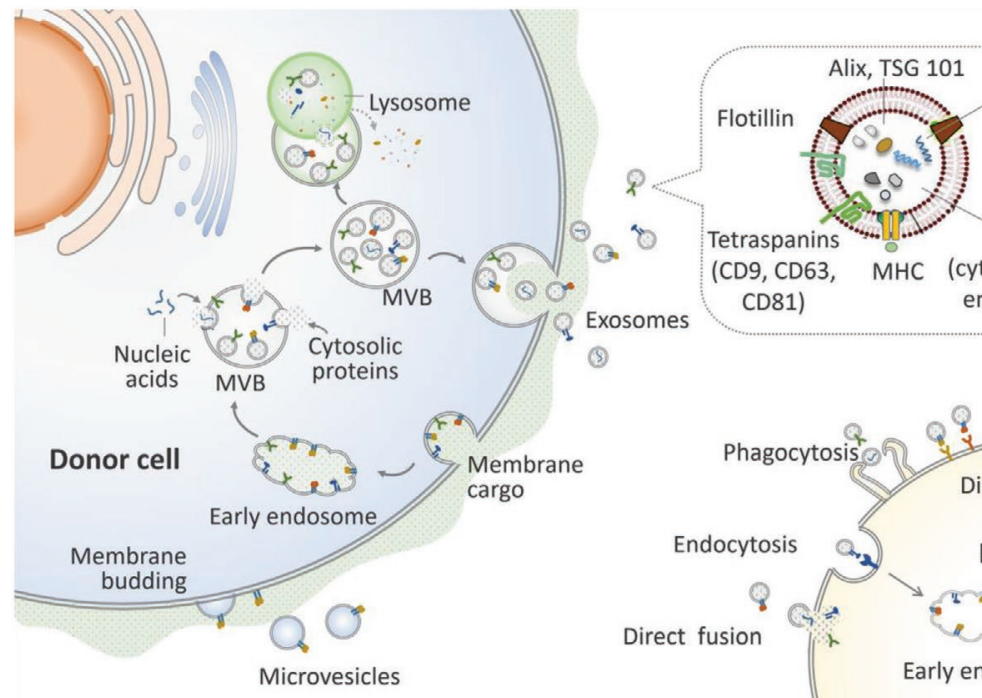

\section{Nucleic acids (gDNA, mtDNA, mRNA, MiRNA, IncRNA, circRNA ) \\ Cytosolic proteins} CD81) cytoskeletal, heat shock, enzyme, RNA-binding)

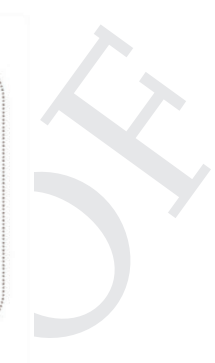

Figure 2. The biogenesis, contents, and internalization of EVs. Exosomes are derived from the fusion of MVBs and plasma membranes. MVs or MPs 20 are formed after direct outward budding of plasma membranes. EVs contain membrane proteins and cytosolic components (nucleic acids and proteins) 21 of donor cells and can transport their cargos to recipient cells though multiple mechanisms such as direct fusion, direct binding (receptor-ligand inter- 22 action), endocytosis or phagocytosis. Abbreviations: gDNA, genomic DNA; IncRNA, long non-coding RNA; MHC, major histocompatibility complex; 23 mtDNA, mitochondrial DNA; MVBs, multivesicular bodies.

physiological and pathological conditions including cancer have been widely reported in the past few decades. ${ }^{[1]}$

Although the mechanisms responsible for specific cargo sorting in EVs are still unclear, previous studies have proposed several possibilities. For example, protein molecules are sorted into MVBs in a ubiquitin-dependent manner with the help of endosomal sorting complex required for transport. In addition, tetraspanin-enriched microdomains also contribute to the sorting of proteins into EVs. ${ }^{[18]}$ For specific loading of RNA (mainly microRNA) into EVs, several key factors such as heterogeneous nuclear ribonucleoprotein A2B1 (hnRNPA2B1), ${ }^{[19]}$ adenylation and urylation at the $3^{\prime}$ end of microRNA (miRNA), ${ }^{[20]}$ argonaute 2 (Ago2), ${ }^{[21]}$ and ubiquitinated form of human antigen $\mathrm{R}(\mathrm{HuR})^{[22]}$ have been reported to be critically involved. Clancy et al. suggest that the interaction between ADP-ribosylation factor 6 (ARF6)-GTP and Exportin-5 promotes pre-miRNA cargo sorting into tumor MVs. ${ }^{[23]}$ Intriguingly, the specific cargos in EVs could reflect the pathophysiological status of their parental cells, which makes them useful biomarkers for monitoring disease progression. ${ }^{[5]}$ The lipid bi-layer membrane structure of EVs not only protects internal proteins and nucleic acids form degradation, but also maintains the inherent targeting abilities from their parental cells, which endows them the potential to serve as an effective carrier for delivering cargos into recipient cells. Moreover, the specific lipidomic and proteomic profiles of EVs may help them escape from endosomal traps and allow for a direct cytosolic delivery of therapeutic cargos..$^{[9,17]}$ These natural and unique properties make EVs ideal NVs for drug delivery.

However, there are some hurdles when translating EVs from bench to bedside. The low isolation yield and complicated purification protocols make massive production of EVs a challenging task. Thus, it is urgently needed to develop standard, scalable, and cost-effective approaches for EV production. In addition, due to the considerable heterogeneity of isolated EVs and their complex composition and structure, it is difficult to 26 characterize EVs as synthetic nanoparticles (NPs) that are cur- 27 rently used in the clinic (e.g., liposomes). Moreover, tedious 28 cargo loading procedures, relatively low delivery efficiency, 29 and unsatisfactory targeting ability also hinder the therapeutic 30 applications of EVs. If these main problems are properly solved, 31 the applicability of EVs as NVs will be greatly advanced. 32

\section{Natural EVs in Cancer Therapy}

The intrinsic ability of EVs to shuttle bioactive molecules has 37 led to extensive exploitation of their function in physiology and 38 pathology. The findings that EVs from immune cells contain 39 bioactive molecules such as major histocompatibility com- 40 plexes (MHC) suggest an immunomodulatory effect of these 41 small vesicles. In 1998, Zitvogel et al. demonstrated that tumor 42 antigen-pulsed, dendritic cell-derived EVs (DEX) can activate T 43 cells to produce anti-tumor effect in established mouse tumor 44 models. ${ }^{[24]}$ Since then, increasing studies have started to explore 45 the potential of natural EVs in cancer therapy (Figure 3). 46

\subsection{DEX and TEX in Cancer Therapy}

Early studies of EVs mainly focus on the potential of dendritic 51 cell- and tumor cell-derived EVs (TEX) as cancer vaccines. ${ }^{[25,26]} 52$ In analogous to their parental cells, DEX present peptide- 53 MHC complexes and a variety of costimulatory molecules on 54 their membrane, which endows them with antigen-presenting 55 ability. ${ }^{[2,27]}$ DEX can also activate natural killer (NK) cells via TNF 56 superfamily ligands. ${ }^{[28]}$ In clinical trials, the administration of 57 DEX into patients with melanoma and non-small cell lung cancer 58 (NSCLC) shows modest T cell activation. In particular, DEX from 59 


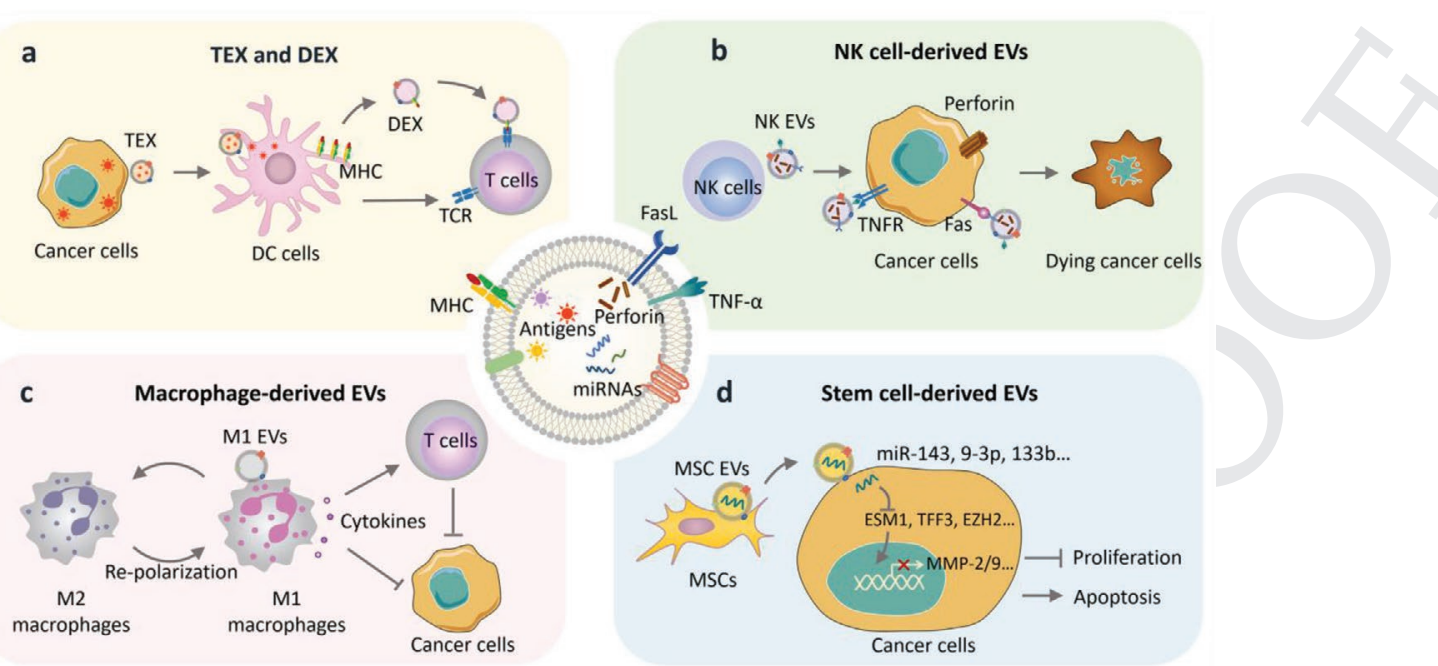

Figure 3. Natural EVs in cancer therapy. a) TEX stimulate immune activation by boosting T-cell expansion and function via APCs especially DC cells DEX activate T cells by mimicking the role of APCs. b) NK cell-derived EVs induce tumor cell death through FasL, perforin, and TNF- $\alpha$. c) EVs from M1 macrophages can re-educate tumor associated macrophages from M2 to M1 phenotype, which further activates anti-tumor immunity. d) Stem cellderived EVs inhibit the growth of tumor cells through miRNA-mediated mechanisms. Abbreviations: DC cell, dendritic cell; DEX, dendritic cell-derived EVs; FasL, Fas ligand; M1 EVs, M1 macrophage-derived EVs; MHC, major histocompatibility complex; MSCs, mesenchymal stem cells; NK EVs, NK cell-derived EVs; TCR, T cell receptor; TEX, tumor cell-derived EVs; TNF- $\alpha$, tumor necrosis factor- $\alpha$; TNFR, tumor necrosis factor receptor.

interferon (IFN)- $\gamma$ maturated DCs boost anti-tumor response of NK cells and achieve better progression-free survival in advanced unresectable NSCLC patients. ${ }^{[29]}$ Although DEX seem to work well in pre-clinical studies, they are difficult to induce highly efficient anti-tumor effects in cancer patients, probably due to the complicated tumor microenvironment. Therefore, in recent years, researchers have further tested the possibility of engineering DEX to improve their therapeutic efficacy.

TEX are used in cancer therapy due to the presence of tumor antigens on their membranes. A common strategy that has been used is to pulse dendritic cells with TEX in vitro, which are then used to stimulate host immune system to boost T-cell expansion and function in vivo. ${ }^{[30]}$ Recently, researchers have collected EVs from the ascites of colon cancer patients and combined them with granulocyte-macrophage colony stimulating factor (GMCSF) for immunotherapy. The combination treatment regimen induces an enhanced specific antitumor T cell immunity, suggesting the feasibility, efficacy, and safety of this strategy. ${ }^{[31]}$ However, the direct use of TEX for cancer therapy is challenged by their participation in almost all aspects of tumor progression, which hinders them to become safe cell-free cancer vaccines. ${ }^{[32]}$

\subsection{NK Cell-Derived EVs in Cancer Therapy}

The ability of NK cells to directly lyse tumor cells in an antigenindependent manner makes them an attractive candidate for cancer therapy. In the past decade, the concept of using EVs from NK cells for cancer therapy has emerged. Lugini et al. demonstrated that EVs from NK cells of healthy donors contain killer proteins such as Fas ligand (FasL) and perforin molecules and can induce remarkable cytolytic activity against leukemia cells. ${ }^{\text {[3] }}$ In another study by Zhu et al., they demonstrated that NK cellderived EVs not only express FasL and perforin, but also produce tumor necrosis factor- $\alpha$ (TNF- $\alpha$ ). NK cell-derived EVs show antitumor effect on melanoma cells but exhibit no significant effect on normal cells. ${ }^{[34]}$ Shoae et al. suggest that EVs from NK cells that have been previously exposed to neuroblastoma (NB) cells educate naive NK cells to exert greater cytotoxicity against NB tumors, which helps to overcome immune resistance of tumor cells. ${ }^{[35]}$ Moreover, NK cell-derived EVs contain tumor suppressive miRNAs (such as miR-186 and miR-3607-3p) that can induce tumor cell apoptosis and inhibit tumor cell proliferation. ${ }^{[36]}$ More importantly, the anti-tumor potential of NK cell-derived EVs can be further enhanced by interleukin (IL)-15 priming. ${ }^{[37]}$ These findings suggest that NK cell-derived EVs have potent anti-tumor activities, which represents a novel approach for cancer therapy.

\subsection{Macrophage-Derived EVs in Cancer Therapy}

Macrophages display diverse phenotypes in response to microenvironment and are categorized into anti-tumor M1 and pro-tumor M2 subtypes. M1 macrophage-derived EVs have been used as an immune potentiator in cancer therapy due to their pro-inflammatory effects. Cheng et al. demonstrated that subcutaneously injected M1 macrophage-derived EVs (M1 EVs) can home to lymph node and induce the expression of pro-inflammatory T-helper cell type 1 (Th1) cytokines such as IL-6 and IL-12, which elicits a strong antigen-specific cytotoxic $T$ cell response and enhances the antitumor effect of nanoparticulate peptide vaccine tyrosinase-related protein-2 (TRP-2), indicating that M1 EVs can be used as a vaccine adjuvant. ${ }^{[38]}$ In addition, Wang and colleagues suggest that M1 EVs can stimulate macrophages in tumor tissues to release cytokines, which establishes a local inflammatory environment that benefits the anti-tumor effects of chemotherapeutic drugs. [39] Moreover, Choo et al. show that EV-like NVs derived from M1 macrophages (M1NVs) can accumulate at tumor sites and
1 2 3 4 5 6 7 8 9 


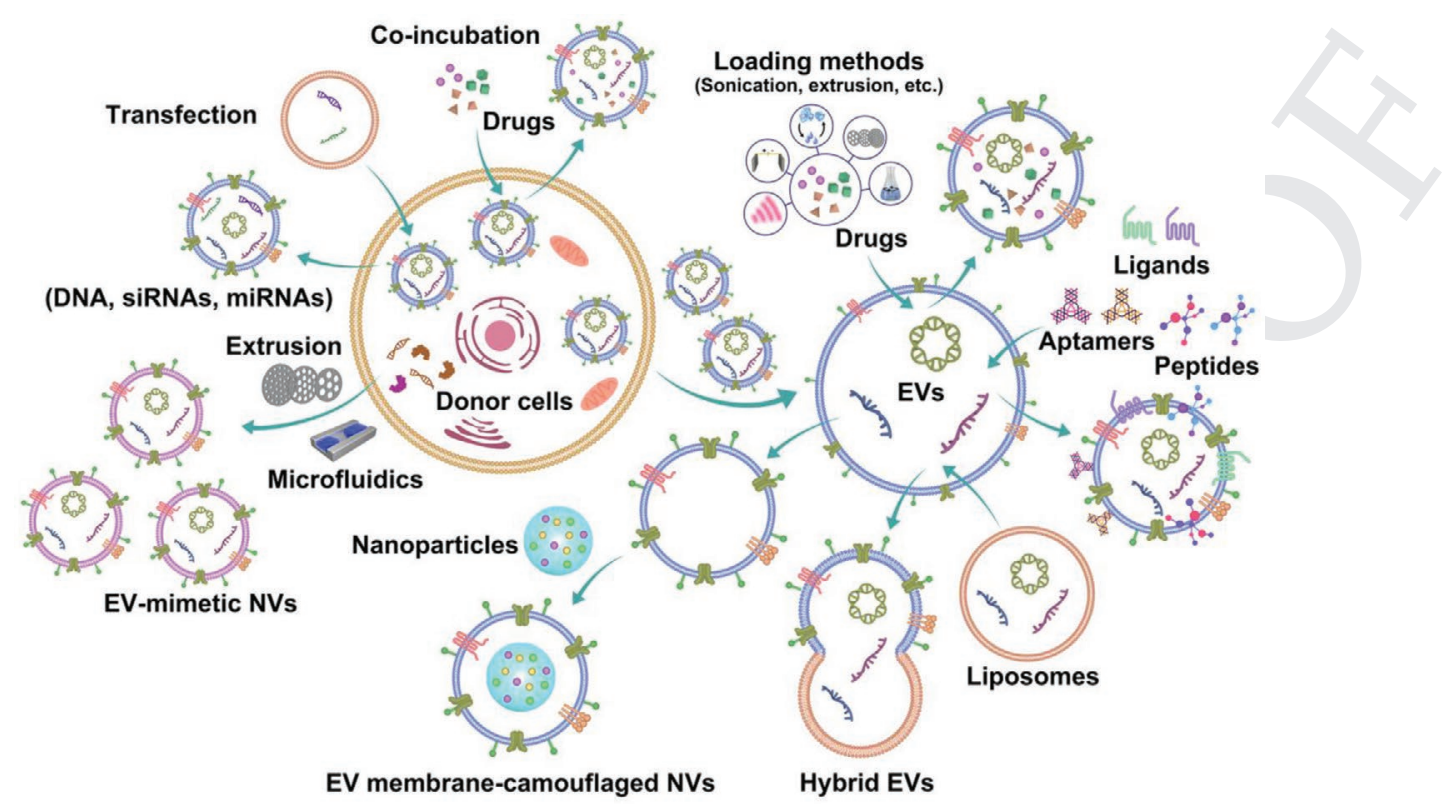

Figure 4. Main strategies for EV engineering. Left: Strategies for engineering donor cells. Co-incubation and gene transfection approaches are used to introduce cargos into donor cells. Extrusion and microfluidic approaches are used to fabricate EV-mimetic NVs and introduce cargos into them. Right: Strategies for EV engineering. Sonication, electroporation, freeze-thaw, extrusion, and saponin permeabilization approaches are used to introduce cargos into EVs. Ligand-displaying strategy is used to anchor targeting ligands, peptides, and aptamers on EV membranes. Nanomaterials including liposomes and micelles can be mixed with EV membranes to fabricate hybrid EVs. Synthetic bio-inspiration strategy is used to develop bio-mimetic EVs. Abbreviations: NVs, nanovesicles.

re-polarize M2 macrophages to M1 macrophages. The combined use of M1NVs improves the anti-tumor efficacy of antiprogrammed death ligand 1 (PD-L1) antibody. ${ }^{[40]}$ Similarly, Fan et al. have generated M1 macrophage-derived artificial vesicles (M1mv) and shown that M1mv exhibit anti-tumor effects by inducing cell apoptosis. ${ }^{[41]}$ These results indicate that M1 macrophage-derived EVs provide a novel anti-tumor therapeutic agent.

\subsection{Stem Cell-Derived EVs in Cancer Therapy}

Several studies have shown that stem cell-derived EVs can suppress cancer progression. For example, EVs from bone marrow mesenchymal stem cells inhibit the growth and metastasis of bladder cancer by miR-9-3p-meiated down-regulation of ESM1 (endothelial cell specific molecule 1) gene expression. ${ }^{[42]}$ In addition, miR-133b in MSC EVs is able to inhibit EZH2 (enhancer of zeste homolog 2) gene expression and block Wnt (wingless) $/ \beta$-catenin signaling pathway, thus suppressing the development of glioma. ${ }^{[43]}$ In prostate cancer, miR-143 from MSC EVs inhibits cancer progression by targeting TFF3 (trefoil factor 3). ${ }^{[4]}$ Intriguingly, the recent studies have shown that combining stem cell-derived EVs with chemotherapy can achieve better therapeutic effects. For instance, EVs from human umbilical cord MSCs enhance the sensitivity of K562 cells to imatinib by activating caspase signaling pathway. ${ }^{[45]}$ Moreover, EVs from irradiated MSCs are able to stimulate tumor cell death and increase their sensitivity to radiation, which may be associated with the enrichment of tumor suppressor genes such as ANXA1 (annexin A1) in these EVs. ${ }^{[46]}$ However, MSC-derived EVs have been described as a double-edged sword in cancer therapy because they also can promote cancer pro- 29 gression. ${ }^{[47]}$ Therefore, the use of natural EVs from stem cells in 30 cancer therapy still needs further investigation. 31

\section{Strategies of EV Engineering}

Proper modification of EVs can increase their delivery effi- 36 ciency, targeting ability, and therapeutic efficacy. ${ }^{[48,49]}$ EVs from 37 different sources, including tumor cells, ${ }^{[50]}$ stem cells, ${ }^{[51,52]} 38$ immune cells, ${ }^{[39,53]}$ human blood and urine, ${ }^{[54,55]}$ and milk, ${ }^{[56]} 39$ have been tested for this purpose. Strategies and methodolo- 40 gies that are commonly used for EV engineering have been well 41 documented in previous reviews and are briefly summarized 42 here. ${ }^{[7,11,15,57]}$ (Figure 4 and Table 1).

\subsection{Approaches for Loading Exogenous Cargos into EVs}

\subsubsection{Active Loading into Donor Cells}

Co-Incubation: Chemical compounds, especially small molecule 50 drugs, can be introduced into EVs by co-incubating them with 51 donor cells at different conditions. For instance, paclitaxel 52 (PTX) is loaded into MSC-derived EVs by incubating MSCs 53 with PTX at $37{ }^{\circ} \mathrm{C}$ for $1 \mathrm{~h}$ with shaking. ${ }^{[58]}$ The similar proce- 54 dure has also been used for loading doxorubicin (DOX) into 55 cancer cell-derived EVs. Although this method is simple and 56 has no major effects on the structure and contents of EVs, the 57 loading efficiency is influenced by drug properties, incubation 58 periods, and other protocol details. ${ }^{[49]}$ 31 42 59 23 24 25

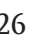
27 28 29 33 34 5 .

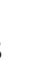

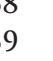
. 年

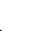
. (

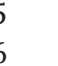
(7) 58 
Table 1. Strategies for cargo loading into EVs.

Advantages
Simple and feasible;
No damage to membrane
integrity

Disadvantages

Prominent examples

\begin{tabular}{c} 
Ref. \\
\hline PTX \\
\hline
\end{tabular}

\begin{tabular}{lc}
\hline Strategies $^{\text {a) }}$ & Methods \\
\hline $\begin{array}{l}\text { Cargo loading into } \\
\text { donor cells }\end{array}$ & Co-incubation \\
& Transfection
\end{tabular}
No damage to membrane integrity

Induce donor cell apoptosis; Impair biological responses; Inefficient packaging

Simple and quick; Higher loading efficiency than transfection

EV aggregation; siRNA precipitation;

Not suitable for some RNAs with special structures

\begin{tabular}{|c|c|c|}
\hline Extrusion & Efficient packaging & $\begin{array}{c}\text { May change the membrane } \\
\text { properties }\end{array}$ \\
\hline Saponin permeabilization & Increase drug loading & Toxicity \\
\hline
\end{tabular}

$$
\text { efficiency }
$$

Freeze and thaw cycles Higher loading efficiency

Sonication

General modification of

EV membrane like NPs

Fusion with membrane proteins

Ligand-displaying

Chimeric EVs

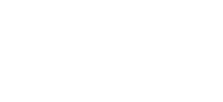

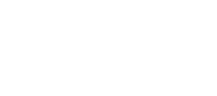

EVs-based platforms

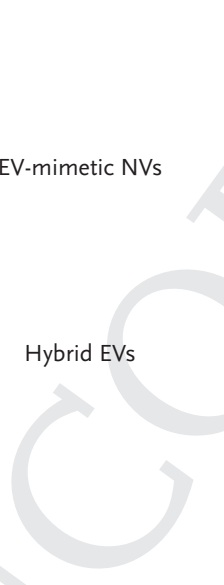

EV membranecamouflaged NVs

Maintain complex EV

\section{Higher loading efficiency \\ Rapid and efficient;}

No damage to membrane integrity

Specific targeting

Specific targeting;

Efficient packaging

Cell membrane and nucleus dual-targeting ability;

Low immunogenicity and systemic toxicity

Simple fabrication procedure;

Controllable preparation process;

Clean identity, high purity and quantity

Maintain membrane structures;

High production yield

Easy preparation and scalability;

Controllable production processes;

Adjustable physical parameters;

Efficient drug loading membrane structure; Specific targeting ability; High therapy efficacy

\section{EV aggregation;}

Lower drug loading capacity than sonication/extrusion

$$
\text { EV aggregation }
$$

May alter the activity of membrane proteins

May affect the functions of cargos in the recipient cells

Synthetic challenge;

Cost of presenting functional ligands

Cost of presenting chimeric peptides

Contain some components of EV membrane but may lose their biological function;

Hard to incorporation multiple components

Low homogeneity and purity; Require additional purification steps;

Less controllable preparation process

May lose biological functions of integral EVs; Increase the difficulty of fabrication;

Low homogeneity

$$
\begin{gathered}
\text { Low scalability; } \\
\text { Increase the difficulty of } \\
\text { fabrication; } \\
\text { Time-consuming }
\end{gathered}
$$

Delivery of Cre recombinase mRNA, let-7c, and HGF siRNA

Delivery of Cy5-labeled miR-26a, HAL, and BACE1 siRNA

$\begin{array}{ccc}\text { Delivery of DOX and PTX } & {[49,58,109]} & 4 \\ & 5 \\ & 6 \\ \text { Delivery of Cre recombinase mRNA, } & {[59]} & 7 \\ \text { let-7c, and HGF siRNA } & & 8 \\ & 9\end{array}$

$[62,63]$

Delivery of hydrophilic porphyrins 14

[61] 15

Delivery of hydrophilic porphyrins

[60] 17

Delivery of catalase

19

20

21

Delivery of DOX and PTX [66,111] $\quad 22$

Targeted delivery of curcumin/SPIONs $\quad[68,69] \quad 23$

and curcumin/cRGD peptide $\quad 24$

25

Targeted delivery of [72] 26

CP05 peptide and IMTP peptide 27

Display folate, PSMA RNA aptamer, [70] 28 and EGFR RNA aptamer 29

Chimeric peptide engineered [139] 31

EV- mediated delivery of

photosensitizer $\quad 33$

Targeted delivery of therapeutic [75] oligonucleotides $\quad 36$

Targeted delivery of CRISPR-Cas9 plasmid and chemotherapeutic drugs

Targeted delivery of proteins, therapeutic RNAs, and imaging agents

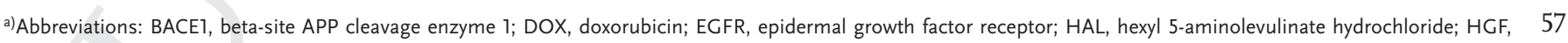

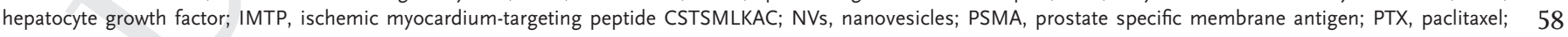
RGD, arginyl-glycyl-aspartic acid; SPIONs, superparamagnetic iron oxide nanoparticles. 
Gene Transfection: Gene transfection is a common strategy for loading cargos into donor cells. Specific cargo-loaded EVs can be obtained from transfected cells by rapid isolation and purification. Exogenous nucleic acids, such as DNA plasmid vector and noncoding RNAs (siRNAs, miRNAs, etc.), are easily to be packaged within EVs through natural biogenesis process. ${ }^{[59]}$ In general, this approach is simple and feasible but has limitations such as poor specificity and low loading efficiency. Further studies are still needed to find ideal donor cells and to improve encapsulation efficiency.

\subsubsection{Passive Loading into EVs}

Passive Mixing: EVs collected from different sources are mixed with various drugs at different conditions to encapsulate drugs. The loading efficiency can be further improved by saponin permeabilization. ${ }^{[6]}$ This method seems to be more frequently used for hydrophobic drugs, because hydrophobic chemicals can interact with and cross hydrophobic EV membrane, thereby increasing drug bioavailability. The loading efficiency appears to be dependent on the hydrophobic nature of the drug while the chemical lipid composition of EVs is also important. ${ }^{[61]}$

Electroporation: EVs and exogenous cargos (such as siRNAs and miRNAs) are mixed in conductive solution under an electrical field to create transit pores on EV membrane, allowing the entry of exogenous cargos into EVs. ${ }^{[62,63]}$ This method may induce EV or siRNA aggregation, thereby affecting the integrity of EVs or therapeutic efficacy of siRNAs. ${ }^{[64]}$

Mechanical Methods: Several mechanical methods are used for cargo loading into EVs, including freeze and thaw cycles, sonication, and extrusion. For freeze and thaw cycles, cargos are incubated with EVs for $30 \mathrm{~min}$ at room temperature and then quickly frozen at $-80{ }^{\circ} \mathrm{C}$ and thawed at room temperature with a repeated procedure for three times. ${ }^{[65]}$ For sonication, EVs and drugs are sonicated on sonic dismembrator ( $20 \%$ amplitude, 6 cycles of $30 \mathrm{~s}$ on/off) with a two-min cooling down procedure between each cycle. For extrusion, EVs and cargos are packaged into a syringe-based hand-held miniextruder with polycarbonate membranes of $400 \mathrm{~nm}$ pore size at $42{ }^{\circ} \mathrm{C}$ and extruded for 30 times. $^{[61]}$ Studies from Kim et al. and Haney et al. indicate that the loading efficiencies of sonication and extrusion are remarkably higher than that of passive mixing and electroporation. ${ }^{[65,66]}$ However, mechanical force on EVs may compromise EV membrane integrity, which will affect their therapeutic activity and bring safety risks for applications.

\subsection{Approaches for EV Modification}

\subsubsection{Modification of EV Membrane}

Proper modification of EV membrane endows them with improved tumor targeting and intracellular delivery capabilities (Figure 4). Chemical modification and gene engineering are two widely used approaches for EV membrane modification. Click chemistry is a copper-catalyzed azide alkyne cyclo-addition reaction that attaches specific molecules into EV membrane. ${ }^{[67]}$ For instance, Jia et al. have conjugated neuropilin-1-targeted peptide (RGERPPR, RGE) to EVs by click chemistry to get glioma- 1 targeting EVs. ${ }^{[68]}$ Tian et al. have conjugated $\mathrm{c}(\mathrm{RGDyK})$ peptide 2 to the surface of DBCO-modified EVs for delivering curcumin to 3 ischemic brain. ${ }^{[69]}$ Moreover, other targeting ligands such as RNA 4 aptamers are displayed on EV membrane by similar procedures. ${ }^{[70]} 5$

The fusion of target protein with EV membrane protein 6 improves their specificity to be loaded into EVs. For instance, 7 Kooijmans et al. have displayed anti-EGFR ligand on EV mem- 8 brane via glycosyl-phosphatidylinositol anchor for tumor cell 9 targeting. ${ }^{[11]}$ In addition, the fusion of targeting peptide with EV 10 marker proteins such as CD63 and Lamp2b, have been com- 11 monly used to acquire targeting EVs. ${ }^{[72]}$ Furthermore, Yim et al. 12 have described a novel targeting delivery tool called exosomes 13 for protein loading through optically reversible protein-protein 14 interactions, which improved the efficiency of loading cargo 15 proteins into EVs under the control of blue light. ${ }^{[73]} 16$

The integration of EV modification and isolation helps rap- 17 idly obtain functionalized EVs. By using a 3D nanostructured 18 microfluidic chip, Wang et al. have prepared EVs chemically 19 labeled with dual ligands (biotin and avidin) and packed drugs 20 into the cytosol. This chemical editing approach facilitated the 21 preparation of EVs with specific targeting ability. ${ }^{[7]}$

\subsubsection{Bio-Inspired /Bio-Mimetic EV Generation and Modification}

Bioinspired or bio-mimetic EVs, including artificially synthe- 27 sized EV-like NPs, EV-mimetic NVs, hybrid EVs, EV membrane- 28 camouflaged NPs, have recently been developed for scalable 29 production, efficient cargo loading, and tumor-targeting. ${ }^{[17]} 30$ Artificially synthesized EV-like NPs refer to those NVs synthe- 31 sized by using individual bio-mimetic molecules such as EV 32 membrane lipids and proteins to resemble the characteristics of 33 EVs. These NPs share similar physiochemical characteristics to 34 natural EVs but display high tumor-targeting ability, providing 35 an alternative platform to natural EVs for drug delivery. ${ }^{[75]} \quad 36$

EV-mimetic NVs are primarily produced by serially extruding 37 donor cells though membrane filters with different sizes of 38 pores or forcing donor cells to move though microchannels 39 of microfluidic devices. ${ }^{[76]}$ Jang et al. have reported the genera- 40 tion of EV-mimetic NVs from monocytes/macrophages with a 41 100 -fold higher production yield. These NVs serve as delivery 42 vehicles for chemotherapeutic drugs and maintain the func- 43 tions of plasma membrane proteins to achieve targeting 44 ability. ${ }^{[7]}$ To facilitate rapid production, Yoon et al. have devel- 45 oped a microfluidic cell-slicing system based on silicon nitride 46 $\left(\mathrm{Si}_{x} \mathrm{~N}_{\gamma}\right)$ blades, which can generate NVs via slicing living cells. ${ }^{[78]} 47$

Hybrid EVs are constructed by fusing EVs with common 48 biomaterials such as liposomes. Lin et al. have mixed plasmid- 49 liposome complex with EVs to obtain hybrid EVs for delivering 50 CRISPR/Cas9 system. ${ }^{[79]}$ Intriguingly, Zhang et al. have con- 51 structed hybrid EVs by integrating red blood cell (RBC) and 52 cancer cell membranes into synthetic phospholipid bilayers, 53 which enables them to inhibit phagocytosis and target homolo- 54 gous cancer cells. ${ }^{[0]}$

EV membrane-camouflaged NPs are formed by coating syn- 56 thesized inner core NPs with EV membrane. These NPs protect 57 loaded cargos from immune clearance and promote intracellular 58 drug release. ${ }^{[81]}$ Bose et al. have coated gold-iron oxide NPs with 59 


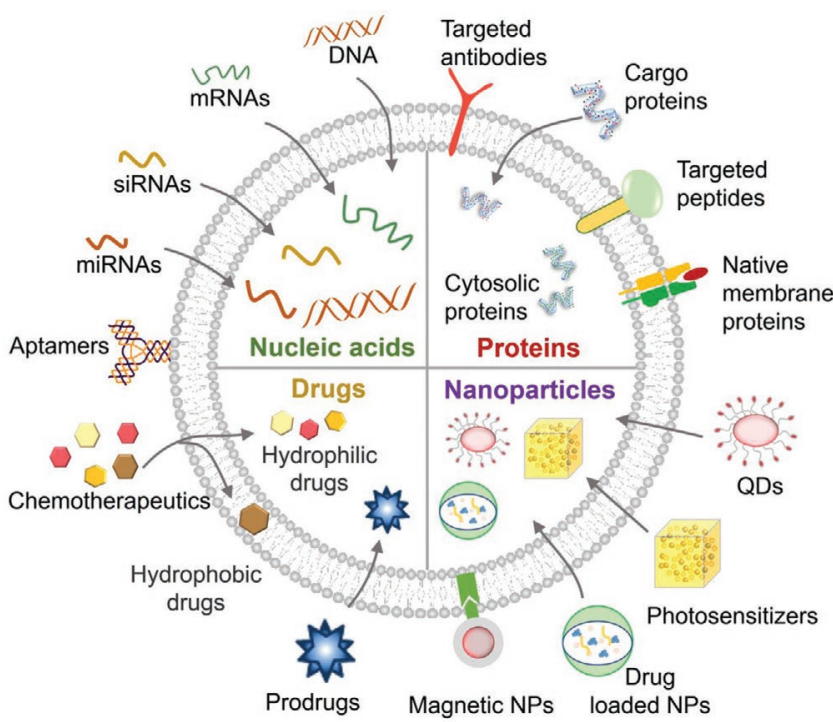

Figure 5. EVs as drug delivery nanovectors. Therapeutic nucleic acids including DNAs and RNAs (mRNAs, miRNAs, and siRNAs) and chemotherapeutic drugs are loaded into EVs. Proteins with targeting abilities or antitumor effects can be incorporated into EVs or anchored on EV membrane. Nanomaterials can be encapsulated by EVs or attached to EV membranes to increase their targeting ability or achieve controllable release. Abbreviations: NPs, nanoparticles; QDs, quantum dots; siRNAs, small interfering RNAs.

the membrane of tumor cell-derived EVs where anti-miR-21 and indocyanine green have been pre-loaded. The multifunctional $\mathrm{NVs}$ show significant tumor-specific accumulation and good potential in imaging, drug delivery, and phototherapy. ${ }^{[82]}$ Liu et al. have developed a microfluidic sonication approach to produce EV membrane-coated, poly (lactic-co-glycolic acid) (PLGA)based NPs for better biocompatibility and targeting efficacy. These EV-biomimetic NPs showed superior homotypic targeting ability and reduced uptake of by monocytes/macrophages. ${ }^{\left[{ }^{83]}\right.}$ Overall, bio-inspired or bio-mimetic EVs are characterized by massive production yield, convenient preparation protocol, and controllable fabrication process, representing a potential alternative to natural EVs for clinical applications.

\section{EVs as Drug Delivery Nanovectors}

Since EVs possess high biocompatibility as well as low systemic toxicity when administrated in vivo, they have been widely used as nanovectors to deliver therapeutic molecules (such as nucleic acids and proteins), drugs, and nanomaterials for cancer therapy (Figure 5 and Table 2).

\subsection{Nucleic Acids}

\subsubsection{DNA}

Targeted delivery of DNA plasmid vector (e.g., CRISPR/Cas9 system) to recipient cells has a great potential for therapeutic genome editing. For instance, CRISPR/Cas9 expression vectors delivered by hybrid EVs achieve efficient in vivo gene manipulation in MSCs. ${ }^{[79]}$ Gee et al. have developed an all-in- 1 one CRISPR/Cas9 ribonucleoprotein delivery platform (Nano- 2 MEDIC) by using EVs, which achieves efficient genome editing 3 in various hard-to-transfect cells, including human induced 4 pluripotent stem cells. ${ }^{[84]}$ Following this strategy, Kim et al. 5 have used cancer cell-derived EVs to efficiently deliver CRISPR/ 6 Cas9 plasmids for targeted inhibition of poly (ADP-ribose) 7 polymerase-1 (PARP-1), ${ }^{[50]}$ which induces apoptosis in ovarian 8 cancer cells and enhances their sensitivity to cisplatin. 9

\subsubsection{RNA}

mRNAs: In vitro and in vivo delivery of interest RNAs hold promise for gene therapy. EVs have been used as delivery vehicles for therapeutic RNAs such as mRNAs, siRNAs, and miRNAs. ${ }^{[10]}$ Mizrak et al. have engineered HEK-293T cells to express high levels of suicide gene and protein-cytosine deaminase (CD) fused to uracil phosphoribosyltransferase (UPRT). ${ }^{[85]}$ The CD-UPRT mRNA/protein complex are loaded into EVs and have tumor cell-killing activity, ${ }^{[86]}$ suggesting a great significance of suicide gene-carrying EVs in cancer therapy. A similar strategy has been used by Kanada et al. ${ }^{[87]}$ and Altanerova et al. ${ }^{[88]}$ to develop EV-based prodrug suicide gene therapy systems, which also achieve promising results.

Cellular nanoporation is a newly developed method to produce large quantities of EVs loaded with therapeutic mRNAs. Yang et al. have used this strategy to incorporate phosphatase and tensin homologue (PTEN) mRNA into EVs with a more than 1000-fold higher loading efficiency than regular transfection. ${ }^{\left[{ }^{[9]}\right.}$ Moreover, to improve the efficiency of message transfer, Kojima et al. have developed a EXOsomal transfer into cells device (EXOtic) to consistently deliver therapeutic mRNA into target cells, indicating the potential of this device for RNA delivery-based therapies. ${ }^{[90]}$

siRNAs: The delivery of siRNAs into specific cells is important for RNA-based therapeutics. Previously, EVs from human blood have been used to transport exogenous siRNAs into monocytes and lymphocytes. ${ }^{[91]}$ Recently, Kamerkar et al. have utilized EVs for delivering siRNAs or shRNAs specific to oncogenic KRAS ${ }^{\text {G12D }}$, with a potent efficacy comparable to liposomes. ${ }^{[92]}$ To improve the efficiency of targeted siRNA delivery, Pi et al. have modified EVs with folate and RNA aptamers to serve as a targeting ligand for binding to specific receptors overexpressed on cancer cells. The engineered EVs are found to successfully deliver survivin siRNAs to prostate and breast cancer cells with less endosome trapping and increased delivery efficiency. ${ }^{[0,93]}$

To prepare high yield of EVs for RNA-based therapeutics, Lunavat et al. have generated EV-mimetic NVs to load c-Myc shRNA. ${ }^{[94]}$ In addition, to achieve improved drug delivery to lung pre-metastatic niche, Zhao et al. have developed bio-mimetic NPs that contain EV membrane-coated NPs and cationic bovine serum albumin (CBSA)-conjugated S100A4 siRNA. The self-assembled NPs protect siRNA from degradation, show excellent biocompatibility and high affinity toward lung, and exhibit outstanding gene silencing effect. ${ }^{[95]}$ Furthermore, to improve siRNA loading efficiency, Reshke et al. have integrated siRNA sequences into the dicer-independent RNA stem-loop (based on pre-miR-451) to improve their sorting

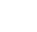

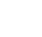

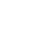
列 列 . 
Table 2. EVs as nanovectors for therapeutic agents.

\begin{tabular}{|c|c|}
\hline Cargo types ${ }^{\text {a) }}$ & Specific substances \\
\hline \multirow[t]{2}{*}{ DNA } & $\begin{array}{l}\text { PARP-1 CRISPR/Cas9 } \\
\text { plasmid }\end{array}$ \\
\hline & $\begin{array}{l}\text { Minicircle DNA } \\
\text { that encodes a TK-NTR } \\
\text { fusion protein }\end{array}$ \\
\hline \multirow[t]{3}{*}{ mRNA } & $\begin{array}{l}\text { CD-UPRT suicide mRNA/ } \\
\text { protein }\end{array}$ \\
\hline & 5-FC and $y C D:: U P R T$ mRNA \\
\hline & PTEN mRNA \\
\hline \multirow[t]{3}{*}{ siRNA } & Kras $^{\mathrm{G} 12 \mathrm{D}}$ siRNA or shRNA \\
\hline & Survivin siRNA \\
\hline & CBSA/sis100A4 \\
\hline \multirow[t]{8}{*}{ miRNA } & anti-miR-214 \\
\hline & miR-122 \\
\hline & miR-206 \\
\hline & miR-26a \\
\hline & miR-126 \\
\hline & miR-146b \\
\hline & miR-124a \\
\hline & anti-miR-9 \\
\hline
\end{tabular}

let-7a miRNA

Proteins Gelonin Survivin-T34A

Targeting peptides (iRGD, etc.)

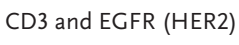

DOX

DOX

DOX, t-PA and photosensitizers

miR-21 responded hairpin Target-triggered drug delivery and induce cancer cell DNA loaded with DOX

$$
\text { PTX }
$$

PTX and AA-PEG

PTX, biotin, and avidin Pd catalysts and prodrug

$$
\text { Ganciclovir, CB1954, and }
$$
TK-NTR

NPs

$$
\text { Magnetic NPs and }
$$$$
\text { photosensitizer }
$$

SPIONs, CPP, and CTNF- $\alpha$

SPIONs, curcumin, and NRP-1 targeted peptide$$
\text { apoptosis }
$$

Alter miR-122 target gene expression
Regulate TRA2B gene and induce cell apoptosis
Inhibit cell cycle gene expression
Interrupt the PTEN/PI3K/AKT signaling pathway
Inhibit EGFR gene expression
Inhibit forkhead box A2 gene expression
Inhibit MDR1 gene expression

$$
\text { Induce cell death }
$$$$
\text { Trigger cell apoptosis }
$$$$
\text { Induce cell apoptosis }
$$

Enhance targeting ability to specific tissues

$$
\text { Recruit and activate cytotoxic T cells }
$$$$
\text { Induce cell apoptosis }
$$$$
\text { Anti-angiogenesis }
$$

Enhance cancer cell death by magnetic targeting

Inhibit cell proliferation

Target the sigma receptor and inhibit cell proliferation

Increase targeting ability and induce cell apoptosis

$$
\begin{aligned}
& \text { Inhibit cell proliferation } \\
& \text { Induce cell apoptosis }
\end{aligned}
$$

Target delivery and induce cell apoptosis

Target delivery and inhibit cell proliferation
Target delivery and enable PDT

$\begin{array}{ccc}\text { Effects } & \text { Cancer types } & \text { Ref. } \\ \begin{array}{c}\text { Induce cancer cell } \\ \text { apoptosis and enhance } \\ \text { chemosensitivity }\end{array} & \text { Ovarian cancer } & {[50]} \\ & & \end{array}$

chemosensitivity

Inhibit tumor growth

Breast cancer

[87]

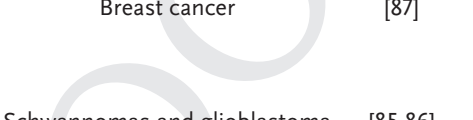

Inhibit tumor growth

Schwannomas and glioblastoma

$[85,86]$

Inhibit tumor growth

Inhibit tumor growth

Inhibit tumor growth

Inhibit tumor growth and progression

Inhibit lung metastasis

Inhibit tumor growth and

reverse chemoresistance

Sensitize cancer cells to

$$
\text { sorafenib }
$$

Inhibit tumor growth

Inhibit tumor growth

Inhibit cancer metastasis

Inhibit tumor growth

Inhibit tumor growth

Reverse TMZ resistance

Inhibit tumor growth

Inhibit tumor growth

Inhibit tumor growth

Enhance therapeutic effect and reduce systemic cytotoxicity

Inhibit tumor growth

Inhibit tumor growth

Inhibit tumor growth

Inhibit tumor growth

Inhibit tumor growth

Inhibit tumor growth

Suppress tumor growth and pulmonary metastasis

Inhibit tumor growth

Inhibit tumor growth

Inhibit tumor growth

Inhibit tumor growth

Inhibit tumor growth

Inhibit tumor growth
Glioma

PTEN-deficient glioblastoma

Pancreatic cancer

Prostate, breast, and colorectal cancers

Triple negative breast cancer

Gastric cancer

$\mathrm{HCC}$

$[88]$

[89]

[92]

[70]

19

[95] 20

[104] 21

22

[99] 23

Osteosarcoma $\quad[98] \quad 25$

HCC [62] 26

$\mathrm{NSCLC}$

[100] 27

Glioma

[102]

[103]

29

Glioma

Glioblastoma

[52]

[101]

Breast cancer

Breast cancer

Pancreatic adenocarcinoma

[81]

[108]

$[109,128]$

Breast cancer and glioblastoma

(a)

Breast cancer

$[147,148]$

Breast cancer

Colorectal cancer

Ovarian and prostate cancers

[109]

[77]

[116]

Breast cancer

[41]

Pancreatic cancer and lung cancer

[56,58]

Lung cancer

[111]

$\mathrm{HCC}$

[74]

NSCLC

Breast cancer

[112]

[87]

Ovarian cancer

$[115,116]$

Melanoma

[134]

Clioma 14 15$$
31
$$

2

3

4

6

8

$$
10
$$

$$
12
$$
17 (18

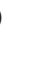

4

6

$$
\begin{aligned}
& 29 \\
& 30
\end{aligned}
$$


Table 2. Continued.

\begin{tabular}{|c|c|c|c|c|c|}
\hline Cargo types a) & Specific substances & Mechanisms & Effects & Cancer types & Ref. \\
\hline & DOX and SPMNs & Enhance targeting ability and induce cell apoptosis & Inhibit tumor growth & Hepatoma & [54] \\
\hline & $\begin{array}{l}\mathrm{Pt}(\mathrm{lau}) \mathrm{NPs}, \mathrm{HSA} \text {, and } \\
\text { lecithin }\end{array}$ & Induce cell apoptosis and suppress cell proliferation & $\begin{array}{l}\text { Inhibit tumor growth and } \\
\text { metastasis }\end{array}$ & Breast cancer & [125] \\
\hline & Nanosensitizer DVDMS & Produce singlet oxygen & $\begin{array}{l}\text { Inhibit tumor growth and } \\
\text { metastasis }\end{array}$ & Breast cancer & [117] \\
\hline
\end{tabular}

a) Abbreviations: 5-FC, 5-fluorocytosine; 5-FU, 5-fluorouraci; AA-PEG, aminoethylanisamide-polyethylene glycol; CBSA, cationic bovine serum albumin; CD, cytosine deaminase; CPP, cell-penetrating peptide; CTNF- $\alpha$, fusion proteins of cell-penetrating peptides and TNF- $\alpha$; DOX, doxorubicin; DVDMS, sinoporphyrin sodium; HSA, human serum albumin; MDR1, multidrug resistance gene 1; NPs, nanoparticles; PARP-1, poly (ADP-ribose) polymerase-1; Pd, palladium; Pt, platinum; Pt(lau), laurate-functionalized Pt(IV) prodrug; PTX, paclitaxel; QDs, quantum dots; RGD, arginyl-glycyl-aspartic acid; SPIONs, superparamagnetic iron oxide nanoparticles; TK-NTR, thymidine kinase-nitroreductase fusion protein; TMZ, temozolomide; t-PA, tissue-plasminogen activator; UPRT, uracil phosphoribosyltransferase.

into EVs. Compared to liposome delivery, this method apparently reduces the therapeutic dose of siRNAs needed to silence target gene expression. ${ }^{[96]}$

miRNAs: MiRNAs are packaged in EVs and transmitted between cells to perform biological functions. ${ }^{[97]}$ Researchers have explored the values of EVs in delivering miRNAs for cancer therapy. MSCs and HEK293T cells are two commonly used cell types for producing miRNA-loaded EVs. The delivery of miRNAs (e.g., miR-206, 26a, 122, 126, 146b, 124a, and let-7a) by MSC-derived EVs has been described in osteosarcoma, ${ }^{[98]}$ hepatocellular carcinoma $(\mathrm{HCC}),{ }^{[62,99]}$ NSCLC, ${ }^{[100]}$ breast cancer, ${ }^{[101]}$ and glioma and shown promising anti-tumor effects. ${ }^{[102,103]}$ The transfer of miRNA inhibitors (anti-miR-9, ${ }^{[52]}$ anti-miR-214, ${ }^{[104]}$ 8 anti-miR-374 $4^{[105]}$ ) by EVs to cancer cells has also been reported. To 29 improve loading efficiency of specific miRNAs into EVs, Li et al. 30 have fused EV marker protein CD9 with HuR, a RNA binding 31 protein that has high affinity with miR-155. Upon cell transfection 32 and EV production, the fused CD9-HuR successfully enriches 33 miR-155 into EVs. ${ }^{[106]}$ Engineered CD9-HuR EVs can also be used 34 to deliver functional miRNA inhibitor, which provides a novel 35 strategy for improved encapsulation of RNA cargo into EVs.

\subsection{Proteins}

Delivery of biofunctional enzymes or therapeutic proteins through systemic administration is hindered by protein degradation and poor cellular uptake. EVs have been suggested as ideal delivery vehicles for functional proteins. ${ }^{[107]}$ For example, Aspe et al. have transfected melanoma cells with dominant-negative mutant (Survivin-T34A) to produce Survivin-T34A-contained EVs. ${ }^{[108]}$ Several studies have reported the modification of EVs through anchoring targeting ligands on their membranes. For instance, EVs engineered to express targeting ligands such as iRGD show highly efficient targeting to $\alpha \mathrm{V}$ integrin-positive breast cancer cells. ${ }^{[109]}$ In similar, Zhao et al. have utilized plasma membrane vesicles that have high affinity with breast cancer cells that express high level of EGFR.[110] Recently, researchers have developed an EV-based, bio-mimetic NP platform to deliver proteins with high efficiency. Therapeutic proteins are caged in the matrix of metal-organic frameworks by self-assembly and the NPs are camouflaged with EV membrane. This bio-mimetic nanosystem protects cargo proteins from degradation and preferentially delivers proteins to tumor sites. ${ }^{[81]}$

\subsection{Drugs}

EV-mediated delivery improves the stability of drugs in the circulation and results in drug accumulation in recipient cells. ${ }^{[54,58,74]}$ Pascucci et al. demonstrated that MSC-derived EVs are able to package and deliver PTX and PTX-containing EVs have a strong anti-proliferative activity on human pancreatic cancer cells. In addition, other cell-derived EVs have also been used for drug delivery. ${ }^{[58]} \mathrm{Kim}$ et al. demonstrated that PTX-loaded, macrophage-derived EVs result in more cytotoxicity in P-gp-positive drug resistant MDCK cells than free drug alone. ${ }^{[66]}$ The same group has developed aminoethylanisamidepolyethylene glycol (AA-PEG) modified, PTX-containing EVs, which show high loading capacity and better anti-cancer effect in a mouse model of pulmonary metastatic lung cancer. ${ }^{[111]}$ To find a more suitable source of EVs for drug delivery, Agrawal et al. have used milk-derived EVs to encapsulate PTX and they show that oral injection of PTX-loaded EVs efficiently inhibits tumor growth. ${ }^{[56]}$ To deliver a catalytic cargo into cancer cells, researchers have loaded palladium (Pd) catalysts into cancer cell-derived EVs. Pd-loaded EVs display a preferential tropism for their progenitor cells and perform catalyst prodrug therapy, ${ }^{[112]}$ suggesting that EV-mediated delivery of catalysts into designated cancer cells may offer a new opportunity for targeted therapy. More recently, Belhadj et al. have developed a combined "eat me/don't eat me" strategy to achieve mononuclear phagocyte system (MPS) escape and efficient drug delivery. ${ }^{[113]}$

\subsection{Nanomaterials}

The combination of EVs with nanomaterials improves targeting ability and therapeutic efficacy. ${ }^{[14]}$ Qi et al. have developed a dual-functional EV-based superparamagnetic nanoparticle cluster (SPMNs) by anchoring multiple superparamagnetic NPs onto blood-derived EVs through transferrin (Tf)-Tf receptor interaction. This strategy shows enhanced cancer targeting and tumor growth inhibition under the external magnetic field in a murine hepatoma cancer model. ${ }^{[54]}$ To generate vesicles with magnetic and optical responsiveness allowing therapeutic and imaging functions, Silva et al. have developed a macrophagederived nanovector loaded with citrate-coated magnetic NPs and $\mathrm{m}$-THPC photosensitizer, named theranosomes. This nanovector can be monitored by dual-mode imaging, which 
Table 3. Engineered EVs for cancer therapy.

Inhil

Therapeutic outcomes

Inhibit peritoneal tumor growth and prolong survival time without typical side effects

\begin{tabular}{|c|c|}
\hline $\begin{array}{c}\text { Human ovarian cancer } \\
\text { cells }\end{array}$ & MPs \\
\hline $\begin{array}{c}\text { Human and mouse } \\
\text { HCC cells }\end{array}$ & Exosomes \\
\hline $\begin{array}{c}\text { Human breast cancer } \\
\text { cells }\end{array}$ & EVs \\
\hline $\begin{array}{c}\text { Mouse macrophages } \\
\text { and liposomes }\end{array}$ & $\begin{array}{l}\text { Exosome- } \\
\text { mimetic NVs }\end{array}$ \\
\hline $\begin{array}{c}\text { Human fibrosarcoma } \\
\text { cells }\end{array}$ & Exosomes \\
\hline Mouse macrophages & $\begin{array}{l}\text { Exosome- } \\
\text { mimetic NVs }\end{array}$ \\
\hline
\end{tabular}

RBCs

Exosome-mimetic NVs

Blood

Exosomes

Mouse macrophages

Exosomes

Mouse macrophages

Exosomes

Targeted

chemotherapy

Mouse macrophages

AA-PEG modified exosomes

Mouse imDCss

iRGD modified exosomes

Macrophages

c-Met binding peptide modified exosomes

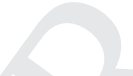

HEK293T cells lipHA-modified EVs

Human embryonic stem $\quad c($ RGDyK) modified

cells exosomes

HEK293T cells

Anti-HER2 affibody

modified liposome-like

NVs

HEK293T cells

hEGF affibody modified liposome-like NVs

\section{CC8 modified EV-like} vesicles

HUVEC

Biotin and avidin modified exosomes

Mouse macrophages Exosome-like NVs

Human colorectal cancer cells

Blood
A33 antibody modified exosomes

SMNC-modified exosomes
DOX

DOX-preloaded PLGA NPs

NPs composed of a Pt Orthotopic breast cancer with prodrug Pt (lau)

PTX

DOX

DOX

PTX prodrug and CuB Breast cancer mouse model loaded nanomicelles

DOX

DOX

DOX

DOX

PTX

Osteosarcoma and breast cancer cells

Fibrosarcoma mouse model

Colon cancer mouse model

$$
\text { cancer mouse model }
$$

Breast cancer mouse model

Orthotopic glioma mouse model

Lung metastases mouse tumor model

Orthotopic breast cancer with
lung metastasis mouse model

Lung metastases mouse tumor model

Breast cancer mouse model

Breast cancer mouse model

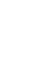

DOX

Lung metastatic breast cancer
MDR breast cancer mouse model

Glioblastoma mouse model

HER2-overexpressing breast cancer mouse model

Breast cancer mouse model Increase PTT effect and inhibit tumor

$$
\text { growth }
$$

NSCLC

HCC mouse model mouse model

Colorectal cancer mouse

$$
\text { model }
$$

$\mathrm{HCC}$ mouse model

Increase tumor accumulation, drug sensitivity, and inhibit tumor growth

Penetrate the BBB, inhibit tumor growth, and prolong survival time

Inhibit tumor growth

Increase tumor accumulation and inhibit tumor growth with reduced systemic toxicity

Inhibit tumor growth

Inhibit lung metastasis vival time without typical side effects

Inhibit tumor growth by targeting

$$
\text { CSCs }
$$

Inhibit tumor growth and capture

CTCs to suppress cancer metastasis

Release drug in acidic condition and

enhance toxicity against cancer cells

Target tumor effectively, enhance

therapeutic retention, and inhibit

$$
\text { tumor growth }
$$

tumor growth to the same

extent as 20-fold higher doses of free

DOX but without typical side effects

decrease systematic clearance, and inhibit tumor growth

Inhibit tumor growth and prolong survival time without typical side effects

Increase cytotoxicity and inhibit lung

$$
\text { metastases }
$$

Inhibit orthotopic and metastatic

$$
\text { tumor growth }
$$

Inhibit lung metastases and prolong

$$
\text { survival time }
$$

Inhibit tumor growth without overt

$$
\text { toxicity }
$$

Possess immune evading ability, target tumor effectively, increase tumor accumulation, and inhibit tumor growth

10

[123]

13

14

[119]

16

17

18

[7] 19

20

21

[80] 22

23

24

[121] 25

26

[66] 27

28

[125] 29

30

[111] 31

32

[109] 33

34

[129] 35

36

37

38

120] 39

40

[128] 41

42

43

Inhibit tumor growth and prolong sur- 
Table 3. Continued.

Methodsa)

EV Sources

EV types

Drugs

Tumour model

Therapeutic outcomes

Ref.

Targeted/

HEK293T cells PSMA or EGFR aptame

folate modified EVs

Prostate, breast cancer mouse

Inhibit tumor growth

therapy

RBCs
Human ovarian cancer
cells
Lipid nanogel

EVs

miR-125b antagonized

$$
\text { model }
$$

myelocytic leukemia mouse model

Inhibit tumor growth without observ- [127]

able cytotoxicity

Ovarian cancer model

Induce apoptosis, enhance chemo-

sensitivity, and inhibit tumor growth

[50] 10 plasmids

Exosomes

anti-miR-214

Cisplatin-resistant gastric cancer mouse model

Enhance chemosensitivity and inhibit tumor growth

\section{Targeted/}

$$
\begin{aligned}
& \text { Urine from gastric } \\
& \text { cancer patients }
\end{aligned}
$$

Human macrophages

Nanovectors

\section{Citrate-coated iron oxide Ovarian cancer mouse model} NPs and the m-THPC

$$
\text { photosensitizer }
$$

Human breast cancer

RGD modified

TAT peptide modified

$$
\text { cells }
$$

exosomes

$$
\mathrm{V}_{2} \mathrm{C} \text { QDs }
$$

Breast cancer mouse model

Human macrophages

RGD modified

DOX and FA-AuNR exosomes

Mouse macrophages NRP-1 targeted peptide Curcumin and SPIONs Orthotopic glioma mouse modified exosomes

$$
\text { model }
$$

Mouse HCC cells

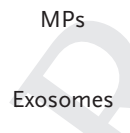

mmunotherapy

Embryonic stem cells

Tumor cells

NK cells

Expi293F cells

Expi293F cells

Tumor cells

Exosomes

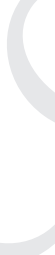

Exosomes

Exosomes

Exosomes

Irradiated tumor cellreleased MPs

$$
\begin{aligned}
& \mathrm{Bi}_{2} \mathrm{Se}_{3} \text { nanodots and } \\
& \text { DOX } \\
& \text { HLA-A2, CD80, CD83 } \\
& \text { and CD137L }
\end{aligned}
$$

HCC mouse model

Not determined

GM-CSF

Lewis lung carcinoma mouse model

Functional $\mathrm{N}$-terminus of HMGN1

miRNA loaded NPs

HCC, pancreatic cancer, and breast cancer mouse models

CD3 and EGFR

antibodies

CD3 and HER2 antibodies

Not determined Not determined
Breast cancer and NB mouse models

Triple negative breast cancer mouse model

HCC mouse model

Malignant pleural effusion mouse model

$$
\text { tumor growth }
$$

Inhibit tumor growth

$$
\text { tumor growth }
$$

\section{destruction}

Inhibit tumor growth

Provide good results for targeted imaging and therapy, penetrate the

$\mathrm{BBB}$ and inhibit tumor growth

$$
\text { Inhibit tumor growth }
$$

Activate $\mathrm{CD} 8^{+} \mathrm{T}$ cells

\section{attacking HER2 $2^{+}$cancer cells}

Repolarize tumor-associated 
Table 3. Continued.

\begin{tabular}{|c|c|c|c|c|c|c|}
\hline Methods ${ }^{\text {a) }}$ & EV Sources & EV types & Drugs & Tumour model & Therapeutic outcomes & Ref. \\
\hline & $\begin{array}{l}\text { Human blood-derived } \\
\text { leukocytes }\end{array}$ & Exosomes & $\begin{array}{l}\text { Melanoma tumor } \\
\text { peptides }\end{array}$ & $\begin{array}{c}\text { Hepatoma and breast cancer } \\
\text { mouse models }\end{array}$ & $\begin{array}{c}\text { Enhance antigen presentation ability } \\
\text { of exosomes and activate } T \text { cells }\end{array}$ & [144] \\
\hline & Mouse melanoma cells & $\begin{array}{l}\text { CpG DNA-modified } \\
\text { exosomes }\end{array}$ & SAV-LA fusion protein & Melanoma mouse model & Inhibit tumor growth & [162] \\
\hline
\end{tabular}

a)Abbreviations: 5-FU, 5-fluorouraci; AA-PEG, aminoethylanisamide-polyethylene glycol; AuNR, gold nanorods; BBB, blood-brain barrier; CC8, integrin $\alpha 3 \beta 1$-binding peptide cNGQGEQc; Ce6, chlorine6; CuB, cucurbitacin B; DM4, cytotoxic soravtansine; FA, folic acid; hEGF, human epidermal growth factor; HLA, human leukocyte antigen; HMGN1, high mobility group nucleosome binding domain protein 1; HUVECs, human umbilical vein endothelial cells; lipHA, lipid mimetic chains-grafted HA; ICC, indocyanine green; MDR1, multidrug resistance gene 1; m-THPC, m-tetra hydroxyphenyl chlorin; MTX, methotrexate; NPs, nanoparticles; PLCA, poly(lactic-co-glycolic acid); PMA, amphiphilic polymer; PSMA, prostate specific membrane antigen; Pt(lau), laurate-functionalized Pt(IV) prodrug; Pt, platinum; QDs, quantum dots; RGD, arginyl-glycyl-aspartic acid; SMNC, superparamagnetic nanoparticle cluster; SPIONs, superparamagnetic iron oxide nanoparticles; $\mathrm{V}_{2} \mathrm{C}$-TAT, vanadium carbide quantum dots modified with TAT peptides.

is valuable in both cancer diagnosis and treatment. ${ }^{[15]}$ They have further enclosed iron oxide NPs and different therapeutic agents into macrophage-derived EVs, which can be manipulated by magnetic force for targeted delivery of drugs. ${ }^{[116]}$ Liu et al. have designed a tumor cell-derived EV-based nanosonosensitizer delivery system, in which high sono-activatable sinoporphyrin sodium (DVDMS) is loaded onto EVs. This system shows targeted accumulation and enhanced DVDMS release under ultrasound exposure, suggesting that EVs are promising delivery vehicles for nanosensitizers..$^{[117]}$

\section{Engineered EVs for Cancer Therapy}

EV-based drug delivery has been assessed in many pre-clinical studies and achieved encouraging results. Compared with their free counterparts, therapeutic molecules and chemotherapeutic drugs encapsulated in EVs are more stable in the circulation, ease to cross physiological barriers, possess superior bioactivity, and show low systemic toxicity. Several ongoing clinical trials are investigating the ability of EVs as delivery vehicles for therapeutic cargos. Some commercial companies such as Codiak BioSciences, Therapeutics Solutions International, and Carmine Therapeutics are developing EV-based cancer therapeutics, suggesting a promising clinical perspective of EVs. To further improve the applicability of EVs in precision cancer therapy, researchers have developed novel strategies to produce EVs with high purity and yield and engineered EVs as drug delivery platforms with high loading efficiency, tumor-targeting ability, and controllable drug release capability (Table 3 ).

\subsection{EVs as Delivery Vehicles for Chemotherapeutic Drugs \\ 6.1.1. Engineered EVs for Delivery of Chemotherapeutic Drugs}

EV-mediated delivery improves the accumulation of chemotherapeutic drugs at tumor sites and reduces the risk of systemic toxicity. ${ }^{[18,119]}$ As a result of the unique integrin expression pattern, EVs from cancer cells preferentially target their 20 parental cancer cells in vitro and home to their original tumor 21 tissues after systemical injection in vivo. ${ }^{[119]}$ EVs-mediated drug 22 delivery also shows high efficacy in the treatment of cancer cells 23 with multi-drug resistance (MDR). Liu et al. demonstrated that 24 HA-functionalized, lipid mimetic chains-grafted HA (lipHA)- 25 modified EVs from HEK293T cells (lipHA-hEVs) enhance the 26 accumulation of DOX in drug resistant breast cancer cells 27 by CD44-mediated cancer-specific targeting and P-gp inhibi- 28 tion. ${ }^{[120]}$ LipHA-hEVs show deep penetration into tumor tissues 29 and effective delivery of DOX into local tumor sites, suggesting 30 that lipHA-hEVs are promising drug carriers for overcoming 31 cancer MDR.

EV-mediated drug delivery can cross blood-brain barrier but 33 the capacity of natural EVs is limited. Bai et al. have developed 34 an EV-based transportation system by using focused ultrasound 35 (FUS), which promotes the BBB-crossing ability of EVs and 36 enhances drug accumulation in glioma cells. The combination 37 of DOX-loaded EVs with FUS treatment results in a remarkable 38 inhibition of tumor growth and an extended survival time with 39 no observable side effects in mouse models, suggesting that it 40 is a potent strategy for brain cancer therapeutics. ${ }^{[121]} \quad 41$

\subsubsection{Bio-mimetic EVs for the delivery of Chemotherapeutic Drugs}

Cell-derived NVs have similar physiochemical properties, such 46 as morphology, size, proteomic and lipidomic profiles, and in 47 vivo biodistribution, to that of natural EVs. The most attractive 48 feature of NVs is that they could be produced with high yield, 49 homogeneity, and purity by a simple preparation procedure. To 50 overcome the relatively low quantities and inconvenient puri- 51 fication of EVs released by mammalian cells, Jang et al. have 52 generated DOX-loaded EV-mimetic NVs from monocytes/ 53 macrophages by serial extrusion. DOX-loaded NVs traffic to 54 tumor tissues after in vivo administration and reduce tumor 55 growth without observable adverse effects. ${ }^{[77]}$ Similarly, Yong 56 et al. have developed EV-mimetic porous silicon nanoparticles 57 (PSiNPs) exocytosed from tumor cells as drug carriers. DOX- 58 loaded PSiNPs are of high tumor accumulation, extravasation, 59 
a
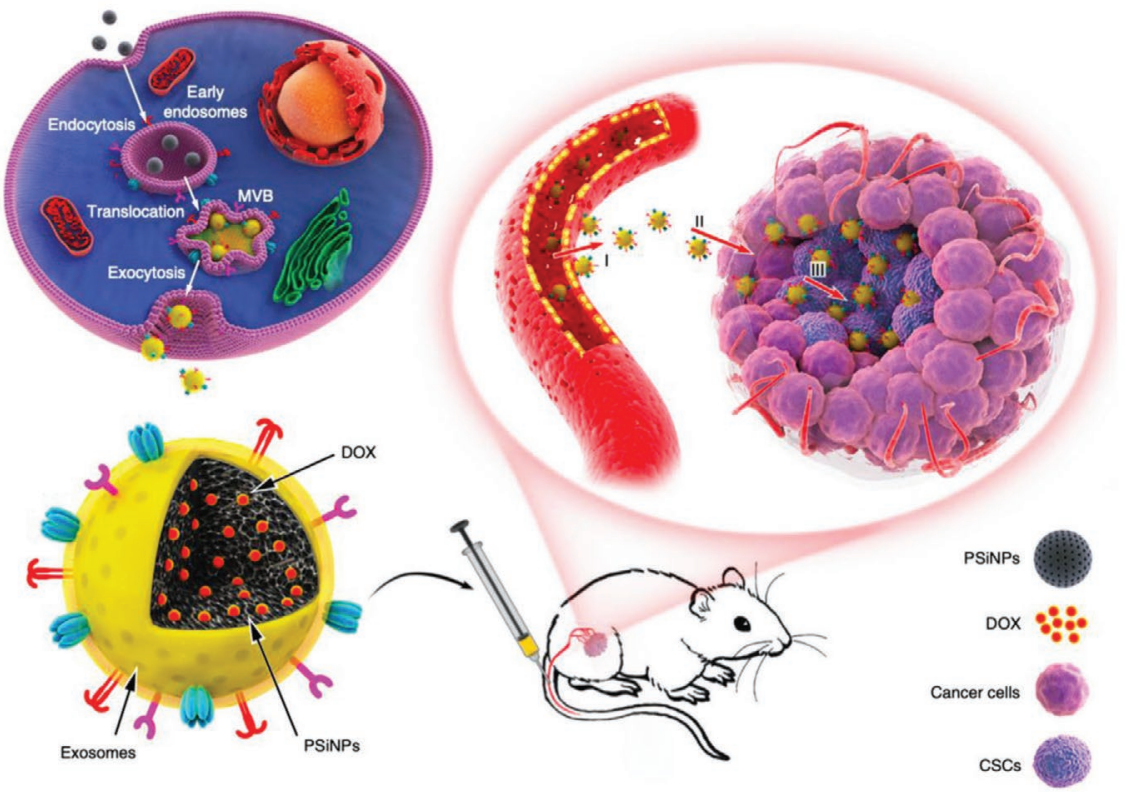

b

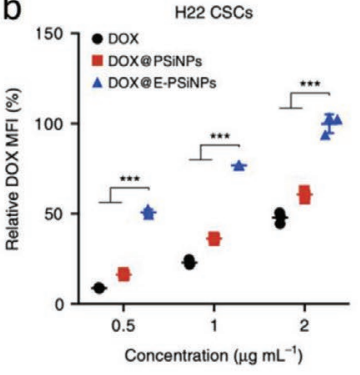

C

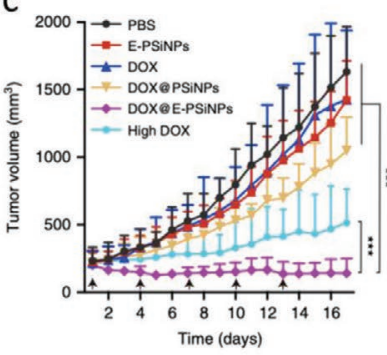

d

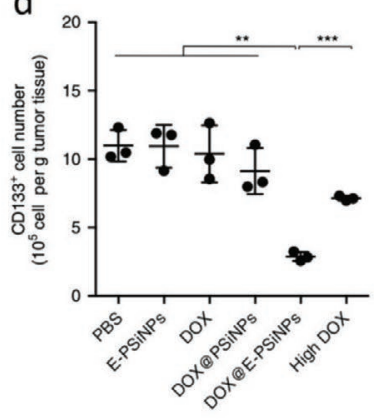

1

Figure 6. EV-biomimetic porous silicon NPs as efficient drug carriers for targeted chemotherapy. a) Schematic illustration of the preparation and the antitumor effect of DOX@exosome-PSiNPs. DOX@PSiNPs are endocytosed into cancer cells after incubation, then exocytosed into extracellular space.DOX@E-PSiNPs show efficient cancer cells and CSCs killing activities after intravenous injection into tumor-bearing mice due to high tumor accumulation, extravasation, and penetration abilities. b) Relative DOX mean fluorescence intensity of H22 CSCs tumor spheroids treated with free DOX, DOX@PSiNPs or DOX@exosome-PSiNPs at different DOX concentrations. c) Time-dependent tumor growth curves of H22 tumor-bearing mice after different treatments. d) Number of CD133-postive cells in tumor tissues at the end of tumor growth inhibition experiments. Abbreviations: MVB, multivesicular bodies; DOX, doxorubicin; PSiNPs, porous silicon nanoparticles; CSCs, cancer stem cells. Reproduced under terms of the CC-BY license. ${ }^{[122]}$ Copyright 2019, Springer Nature.

and penetration abilities and exhibit enhanced antitumor and cancer stem cell (CSC)-killing activities in multiple cancer models (Figure 6). ${ }^{[122]}$ More recently, Wang et al. have coencapsulated PTX prodrug PTX-S-LA and cucurbitacin B (CuB) into nanomicelles and then coated them with EV membrane via extrusion. This EV-mimetic prodrug nanoplatform targets primary tumor and capture circulating tumor cells (CTCs) to suppress cancer metastasis, which provides a novel platform for intercellular controlled release of therapeutic agents. ${ }^{[123]}$

Hybrid EVs combine the benefits of synthetic NPs with the intrinsic advantages of EVs, providing a safe and efficient system for drug delivery. Rayamajhi et al. have engineered macrophage-derived EVs with synthetic liposomes to become a refined bio-mimetic hybrid EVs for the delivery of DOX. They demonstrated that drug-loaded hybrid EVs show enhanced toxicity against cancer cells and $\mathrm{pH}$-sensitive drug release in acidic condition, which benefits drug delivery to acidic cancer environment for targeted therapy. ${ }^{[124]}$ By using a similar strategy, Zhang et al. have developed bio-mimetic artificial chimeric EVs (ACEs) as drug delivery nanovehicles by integrating cell membrane proteins from RBCs and cancer cells into synthetic phospholipid bilayers. DOX-loaded ACEs obtain increased tumor accumulation, reduced liver retention, and improved antitumor effects compared to DOX-loaded liposomes (Figure 7). ${ }^{[80]}$ Moreover, Xiong et al. have designed bio-inspired EVs that could encapsulate Pt anti-cancer drugs for the therapy of orthotopic breast cancer with lung metastasis. ${ }^{[125]}$ Taken together, these findings suggest that the use of bio-inspired or bio-mimetic EVs to deliver chemotherapeutic drugs further expands the applicability of EVs in cancer therapy and achieves promising therapeutic effects in primary, metastatic, and drug-resistant cancers. 
a
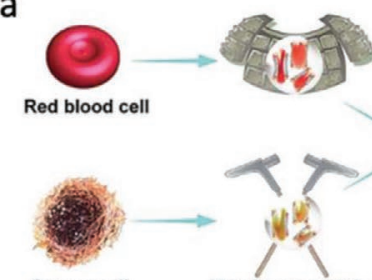

Cancer cell
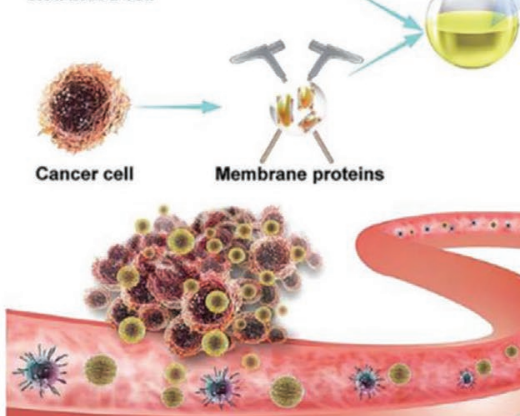
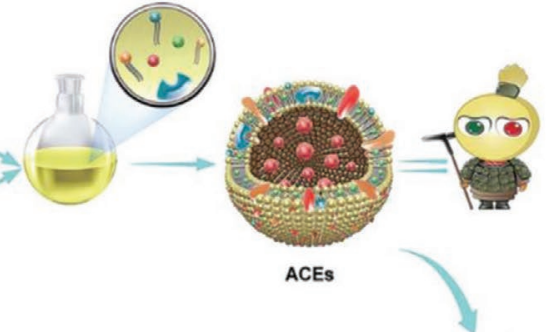

1

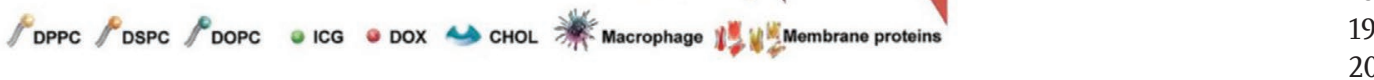

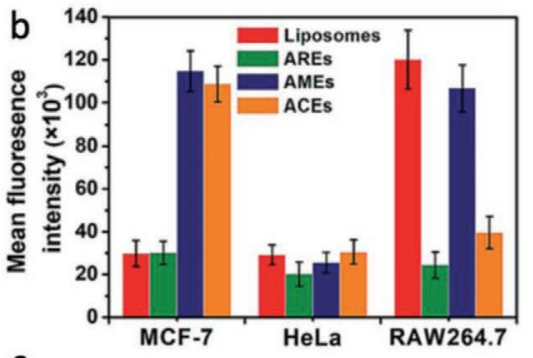

C

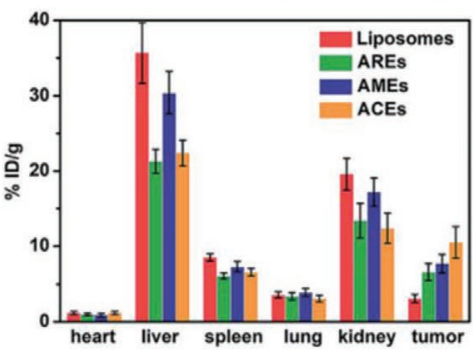

d

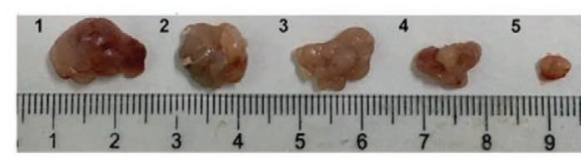

Figure 7. Bio-mimetic ACEs as drug delivery nanovehicles for targeted cancer therapy. a) Schematic illustration of the design of biomimetic ACEs for anti-phagocytosis and targeted cancer therapy. b) Averaged DOX fluorescence intensity of MCF-7 cells, HeLa cells, and RAW264.7 cells after incubation of ACEs for $2 \mathrm{~h}$. c) Biodistribution of DOX at $24 \mathrm{~h}$ after intravenous administration of ACEs to breast tumor-bearing nude mice. d) Tumor tissues obtained from tumor-bearing mice after treatment with PBS, liposomes, AREs, AMEs, and ACEs. e) Tumor growth curves of different groups after treatments. Abbreviations: ACEs, artificial chimeric EVs; AMEs, artificial MCF-7 cell EVs; AREs, artificial RBC EVs; CHOL, cholesterol; DOPC, 1,2-dioleoylsn-glycero-3-phosphocholine; DOX, doxorubicin; DPPC, 1,2-dihexadecanoyl-rac-glycero-3-phosphocholine; DSPC, distearoyl phosphatidylcholine; ICG, indocyanine green. Reproduced with permission. ${ }^{[80]}$ Copyright 2019, The Royal Society of Chemistry.

\subsection{EVs as Delivery Vehicles for Therapeutic Nucleic Acids}

Gene therapy targets the diseased genome with high specificity and great flexibility. There is still a lack of safe and effective strategies for the delivery of therapeutic RNAs to most primary tumor tissues. A pioneer study from Kamerkar et al. has shown that iExosomes (EVs engineered to carry Kras ${ }^{\mathrm{G} 12 \mathrm{D}}$ siRNAs or shRNAs) escape from phagocytosis by monocytes/ macrophages through CD47-mediated "don't eat me" signal. Treatment with iExosomes inhibits pancreatic cancer growth and metastasis in mouse models and significantly increases overall survival, which suggests a new approach for pancreatic 49 cancer therapy. ${ }^{[92]}$ Subsequently, the same group has estab- 50 lished a bioreactor-based, large-scale production of clinical- 51 grade iExosomes employing good manufacturing practice 52 (GMP) standards, ${ }^{[126]}$ which has been recently approved by FDA 53 to enter into phase I clinical trial.

Human RBCs represent an ideal source for large-scale EV 55 production since they are readily available in blood banks and 56 devoid of DNA. Usman et al. have developed an interesting 57 strategy to generate large-scale amounts of RBC-derived EVs 58 (RBCEVs) for the delivery of RNA drugs such as antisense 59 
oligonucleotides (ASOs) that antagonize oncogenic miR-125b, which significantly inhibits cancer growth with no observable cytotoxicity. ${ }^{[127]}$ RBCEV platform is also useful for CRISPR/ Cas9 system-mediated genome editing. Treatment of leukemia cells with RBCEVs loaded with Cas9 mRNA and 125b-gRNA results in almost complete reduction of miR-125b expression. These findings suggest that RBCEVs is an efficient and versatile delivery system for therapeutic RNAs.

\subsection{EVs as Nanocarriers for Targeted and Combined Therapy}

\subsubsection{Engineered EVs as Delivery Vehicles for Targeted Chemotherapy}

Targeted delivery of chemotherapeutic drugs to tumors remains a major challenge for precision medicine. The intrinsic targeting capacity of natural EVs is still unsatisfactory. To this end, increasing studies have explored the potential use of EVs for targeted therapy by specific cargo loading and surface modification. The decoration of EVs with functional ligands is a commonly used strategy to endow them with increased stability in the bloodstream, tropism toward tumor sites, and intracellular delivery of drugs. For example, Tian et al. have modified mouse immature dendritic cells (imDCs) with iRGD peptide and used their derived EVs as drug carriers to target $\alpha \mathrm{V}$ integrin-positive breast cancer cells. ${ }^{[109]}$ In a recent study by $\mathrm{Zhu}$ et al., they demonstrated that c(RGDyK)-modified, PTX-loaded embryonic stem cell-derived EVs penetrate blood-brain barrier to decrease glioblastoma growth more effectively than free PTX and their unmodified counterparts. ${ }^{[128]}$ Furthermore, Li et al. demonstrated that macrophage-derived EVs loaded with DOX-preloaded PLGA nanoparticles and decorated with a c-Met binding peptide possess excellent immune evading ability and exhibit enhanced tumor-targeting capability. ${ }^{[129]}$ These findings suggest that proper modification of EVs can improve their targeting ability and therapeutic efficacy.

Using bio-mimetic synthetic strategy, Zhang et al. have prepared bio-functionalized liposome-like NVs (BLNs) that can display targeting ligands (such as EGF and anti-HER2 affibody) and encapsulate anti-cancer drugs (such as DOX). Treatment with anti-HER2 affibody-displayed, DOX-loaded BLNs exhibits much better anti-tumor effects than clinically approved liposomal DOX in HER2-positive mouse breast cancer models. ${ }^{[130]}$ Similarly, Lin et al. have encapsulated imperialine into plasma derived EV-like vesicles (ELVs) followed by attaching integrin $\alpha 3 \beta 1$-binding peptide cNGQGEQc (CC8) to their surface for NSCLC cell-targeting chemotherapy. Imperialine-loaded CC8ELVs show increased drug concentration in tumors and strong anti-tumor activity with low systemic toxicity. ${ }^{[131]}$

To specifically deliver drugs to metastatic tumors, Cao et al. have constructed EV-like NVs that are loaded with soravtansine (a prodrug of DM4) and anchored with legumain-specific propeptide of melittin (legM) on their membrane. ${ }^{[132]}$ In response to internalization by metastatic breast cancer cells and activation by legumain protease, the prodrug encapsulated in primary NVs convert to facilitate cell death. Then, the damaged cells generate secondary NVs to further release free drug and destroy neighboring cancer cells. This smart drug delivery 1 system displays improved targeting ability for lung metastatic 2 lesions and remarkably inhibits lung metastasis in vivo, pro- 3 viding a new delivery vehicle with controllable drug release for 4 metastatic lung cancer therapy.

The combination of EVs with superparamagnetic iron oxide nanoparticles (SPIONs) further increases their targeting ability. ${ }^{[133]}$ Using this strategy, Qi et al. have developed a blood EV-based SPMNs as targeted drug delivery vehicle for cancer therapy, which can be rapidly separated from blood and exhibit strong responsiveness to external magnetic field to target cancer cells. ${ }^{[54]}$ Jia et al. have loaded SPIONs and curcumin into EVs and then conjugated EV membrane with neuropilin-1 targeted peptide. SPION-mediated magnetic flow hyperthermia and curcumin-mediated therapy show a potent synergistic antitumor effect, which achieves dualtargeting abilities and potent therapeutic effects. ${ }^{[68]}$ To improve the therapeutic effect of TNF- $\alpha$, Rao et al. have developed cellpenetrating peptides (CPP) and TNF- $\alpha$ (CTNF- $\alpha$ )-anchored EVs coupled with SPIONs, which enhances cancer targeting and efficiently inhibit melanoma growth (Figure 8). ${ }^{[134]}$

\subsubsection{Engineered EVs as Delivery Systems for Gene/Drug} Synergistic Therapy

Drug resistance is recognized as the main cause of chemotherapy failure. The efficient inhibition of highly drug-resistant tumors still remains a big challenge. The strategy of co-delivering functional small RNAs and anti-cancer drugs by EVs suggests a potential approach to reverse drug resistance. Wang et al. have designed a bio-mimetic lipid/dextran hybrid nanocarrier loaded with MDR1-siRNA and PTX. The knockdown of MDR1 by siRNA promotes the accumulation of PTX in cells, thus achieving an efficient inhibition of highly resistant cancer cells. ${ }^{[135]}$

To improve the targeting ability of EV-based gene manipulation, Fan et al. have constructed a target-triggered drug delivery system by engineering EV-like vesicles of M1 macrophages with miR-21-responded hairpin DNA and loading them with DOX. The engineered M1mv showed reinforced specificity of drug release and stronger anti-tumor effects. ${ }^{[11]}$ Using the similar strategy, Liang et al. have used anti-HER2 affibody-displayed EVs which encapsulate miR-21 inhibitor and 5-FU to reverse drug resistance in colon cancer. ${ }^{[136]}$

To co-deliver drugs and nucleic acids to tumor cells precisely, Zhan et al. have recently constructed a nanoplatform where DOX and cholesterol-modified miR-21 inhibitor are loaded into blood EVs, while SPIONs and endosomolytic peptides L17E are attached to EV membrane to improve endosome escape ability and tumor accumulation. This system exhibits efficient inhibition of tumor growth in vivo, demonstrating the potential of the "multi-in-one" nanoplatform in cancer therapy (Figure 9). ${ }^{[137]}$

\subsubsection{Engineered EVs as Delivery Systems for Cancer-Targeted Photothermal Therapy}

Photothermal therapy (PTT) and photodynamic therapy (PDT) are two hyperthermia therapeutic methods that usually (1) 3 4 
a
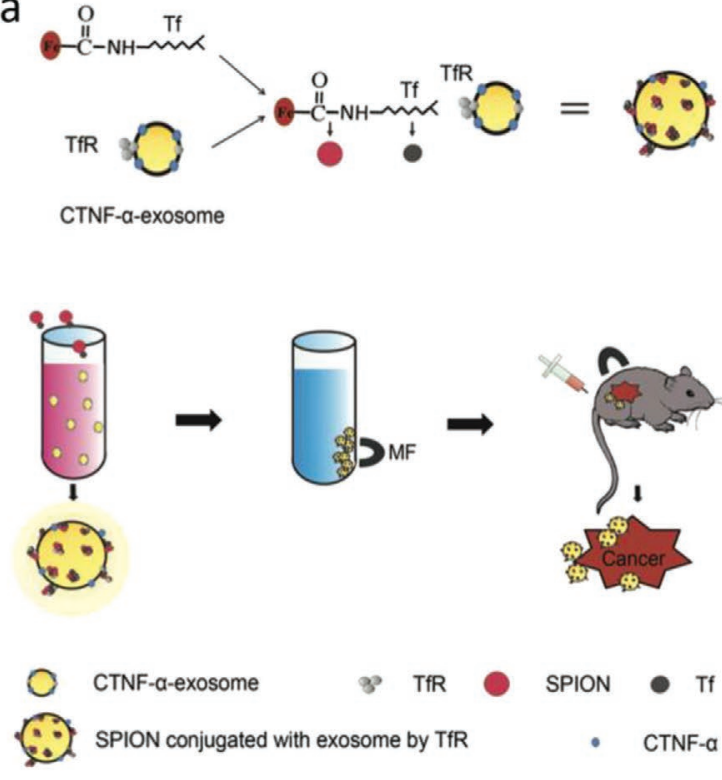

b
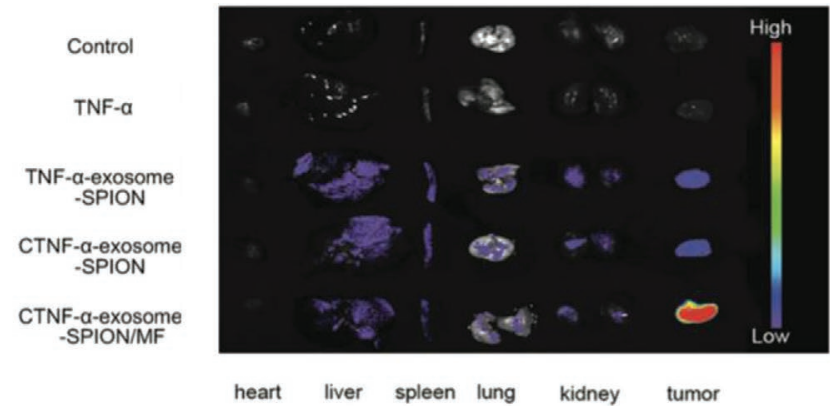

C

Figure 8. SPIONs-decorated EVs targetedly deliver TNF- $\alpha$ to cancer cell membrane and inhibit tumor growth. a) Schematic illustration for the preparation and targeting ability of the CTNF- $\alpha$-EV-SPION. b) NIRF optical images of tumors and major organs after intravenous injection in the absence or presence of external magnetic field. c) Tumor growth monitored at different time-points and volume calculation. d) Tumor tissues obtained from tumor-bearing mice after different treatments. Abbreviations: CTNF- $\alpha$, fusion proteins of cell-penetrating peptides and TNF- $\alpha$; MF, magnetic field; NIRF, near-infrared fluorescence; SPION, superparamagnetic iron oxide nanoparticle; Tf, transferrin; TfR, transferrin receptor; TNF- $\alpha$, tumor necrosis factor- $\alpha$. Reproduced with permission. ${ }^{[134]}$ Copyright 2019, The Royal Society of Chemistry.

employ light-absorbing agents to kill cancer cells under laser irradiation. To achieve effective chemo-photothermal anti-tumor treatment, Wang et al. have designed a photoresponsive EV system that can effectively accumulate at tumor sites via dual ligand (FA and RGD)-mediated endocytosis (Figure 10). ${ }^{[138]}$ The localized hyperthermia induced by the conjugated gold nanorods (AuNR) under near-infrared irradiation (NIR) impacts the permeability of EV membrane to enhance drug release, thus inhibiting tumor relapse in a programmable manner.

Following a dual-stage light PDT strategy, Cheng et al. have engineered EVs with chimeric peptide (ChiP-Exo) to exert their activities by sequentially destroying the plasma membrane and nucleus of tumor cells. This strategy exhibits an elevated tumor targeting delivery and a greater tumor growth inhibition with minimized systemic toxicity, providing a new tool for precise tumor therapy. ${ }^{[139]}$ To achieve effective tumor killing, Cao et al. have applied a combined strategy that engineers EV with vanadium carbide quantum dots $\left(\mathrm{V}_{2} \mathrm{C} \mathrm{QDs}\right)$ and photothermal agents for low-temperature nucleus-targeted PTT in NIR-II region (Figure 11). ${ }^{[140]}$ The $\mathrm{V}_{2} \mathrm{C}$ QDs are modified with TAT (transactivator of transcription) peptides and packaged into EVs followed by RGD modification. The resulting NPs exhibit good biocompatibility, long circulation time, and endosomal escape ability, and thus enter into the nucleus to perform low-temperature PTT with improved anti-tumor effect.

To solve the problems of EVs for clinical application such as unsatisfied yield, complicated labeling procedure, and low drug loading efficiency, Pan et al. have obtained high-purity urinary EVs from gastric cancer patients and efficiently loaded them with multi-functionalized PMA/Au-BSA@Ce6 NPs via electroporation. The engineered nanovehicles are efficiently inter- nalized into cancer cells due to reduced endocytosis of mac- 29 rophages and prolonged blood retention time. In response to 30 laser irradiation and acidic condition, the engineered nanovehi- 31 cles are broken and tremendous NPs are released inside, pro- 32 ducing considerable singlet oxygen and thus inhibiting tumor 33 cell growth. ${ }^{[55]}$ To achieve comprehensive therapy, Wang et al. 34 have pre-loaded $\mathrm{Bi}_{2} \mathrm{Se}_{3}$ nanodots and DOX into tumor cells via 35 electroporation and obtained MPs ( $\left.\mathrm{Bi}_{2} \mathrm{Se}_{3} / \mathrm{DOX} @ \mathrm{MPs}\right)$ through 36 irradiation-induced budding. $\mathrm{Bi}_{2} \mathrm{Se}_{3} / \mathrm{DOX} @ \mathrm{MPs}$ show syner- 37 gistic antitumor efficacy by combining PTT with low-dose chem- 38 otherapy. ${ }^{[141]}$ These findings suggest that engineered EVs provide 39 an efficient and safe delivery system for targeted PTT of cancers. 40

\subsection{EVs as Nanocarriers for Immunotherapy}

Engineered EVs have been used for improved cancer immunotherapy. ${ }^{[142]}$ For instance, Sueon et al. have constructed human leukemia K562 cells that stably express human leukocyte 47 antigen and various costimulatory molecules to act as artificial 48 antigen presenting cell. EVs from modified K562 cells acti- 49 vate $\mathrm{CD}^{+} \mathrm{T}$ cells more strongly than their unmodified coun- 50 terparts. ${ }^{[143]}$ Zhao et al. have prepared EVs from murine APCs 51 that have been decorated with tumor peptides on the surface 52 and developed a microfluidic platform for automated and rapid 53 purification. Engineered EVs induce significant higher antigen- 54 specific $\mathrm{CD}^{+} \mathrm{T}$ cell proliferation than native, non-engineered 55 counterparts. ${ }^{[144]}$

In addition, Kavitha et al. suggest that EVs from GM-CSF- 57 expressing embryonic stem cells have immunogenicity similar 58 to tumor EVs and GM-CSF enhances their immune response 59 
a

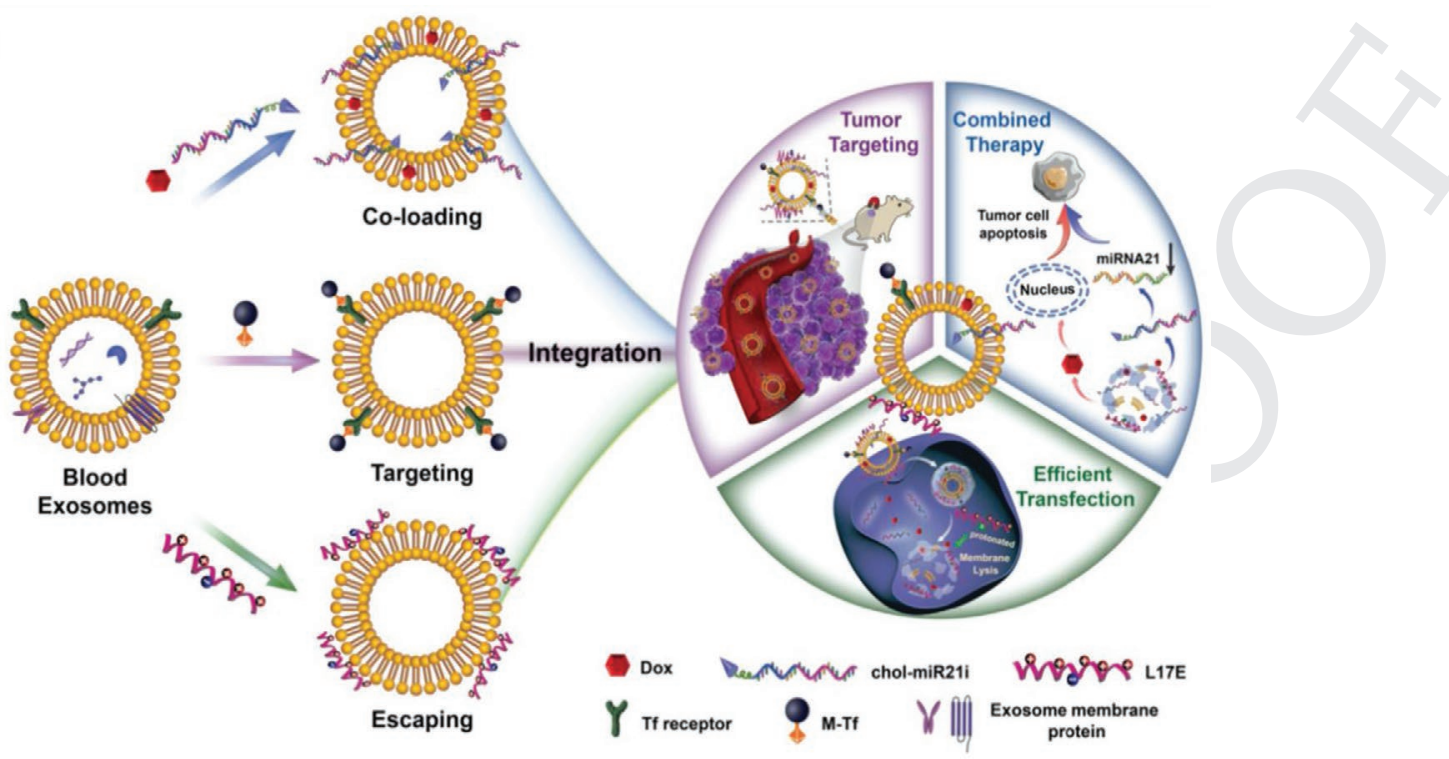

b

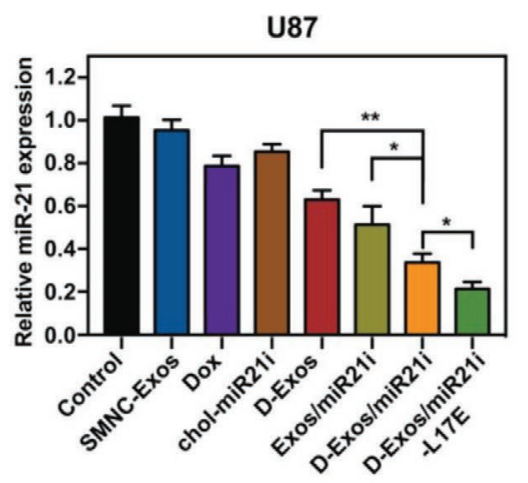

C

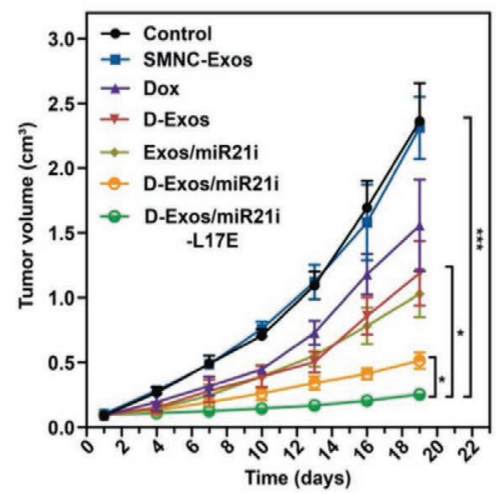

1 2 3

Figure 9. Engineering blood EVs for targeted gene/drug synergistic therapy. a) Schematic illustration of the design and combined antitumor effects of blood EV-based "multi-in-one" nanosystem. b) Relative expression levels of miR-21 in U87 cells after treatment with different samples. c) Tumor growth curves of U87 tumor-bearing mice after different treatments. Abbreviations: Chol-miR21i, cholesterol-modified miRNA21 inhibitor; DOX, doxorubicin; Tf, transferrin. Reproduced under terms of the CC-BY license. ${ }^{[137]}$ Copyright 2020, Ivyspring International Publisher.

ability, which shows considerable anti-tumor effects in mice and thus can be developed as tumor preventative vaccines. ${ }^{[51]}$ Chimeric antigen receptor T-cell immunotherapy (CAR-T therapy) is a promising novel cancer therapy but show unique toxicities. Fu et al. suggest that CAR-T cell-derived EVs that carry CAR on their surface can directly attack tumor cells in a relatively safe way compared to CAR-T therapy. Moreover, CAR EVs do not express immune checkpoint molecule programmed cell death protein 1 (PD1), which maintains their anti-tumor effect not to be compromised by PD-L1 in tumor cells. ${ }^{[53]}$

To potentiate DC immunogenicity and improve vaccine efficiency, Zuo et al. have constructed TEXs that are decorated with the functional domain of high-mobility group nucleosome binding domain 1 (HMGN1) via an anchor peptide. ${ }^{145]}$ DCs pulsed by the engineered TEXs show increased homing ability to lymphoid tissues and enhance memory $\mathrm{T}$ cell response, resulting in long-term anti-tumor immunity and tumor inhibition effect in tumor-bearing mouse models. Moreover, Wang et al. suggest a cocktail strategy based on NK cell-derived
EVs. Bio-mimetic core-shell NPs are self-assembled with a dendrimer core loading therapeutic miRNA such as let-7a and a hydrophilic shell of NK cell-derived EVs. The resulting NN cocktail shows highly efficient targeting and therapeutic miRNA delivery to NB cells in vivo, leading to dual tumor growth inhibition effects. ${ }^{[146]}$

To reinforce the immunogenicity of EVs, Cheng et al. have developed synthetic antibodies-targeted EVs (SMART-EVs) by genetically displaying two distinct types of antibodies on EV membrane, including monoclonal antibodies specific for $\mathrm{T}$ cell CD3 and cancer cell-associated EGFR. SMART-EVs act as an artificial cellular immunity controller to redirect immune effector cells and show potent anti-cancer immunity against EGFR-positive breast cancer cells. ${ }^{[147]}$ The same group has also generated SMART-EVs that express anti-human CD3 and anti-human HER2 antibodies. ${ }^{[148]}$ The resulting SMARTEVs recruit human T cells to kill HER2-positive breast cancer cells, indicating that this strategy is useful for targeted cancer immunotherapy. 

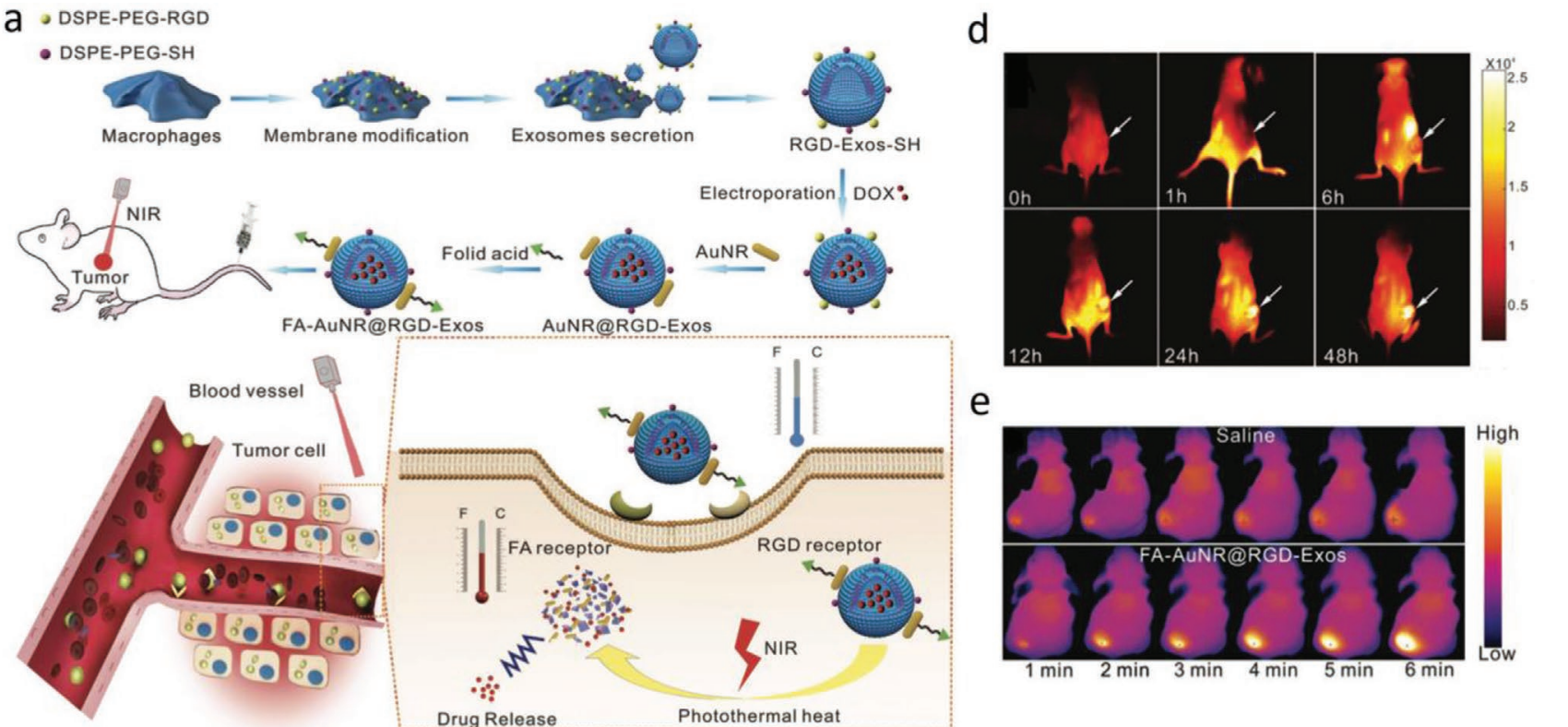

e

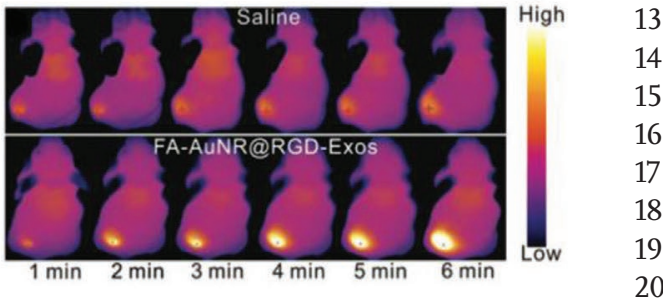

b

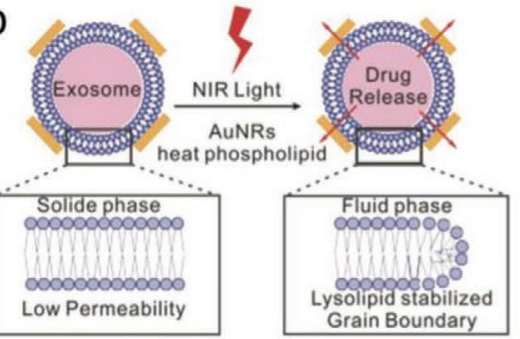

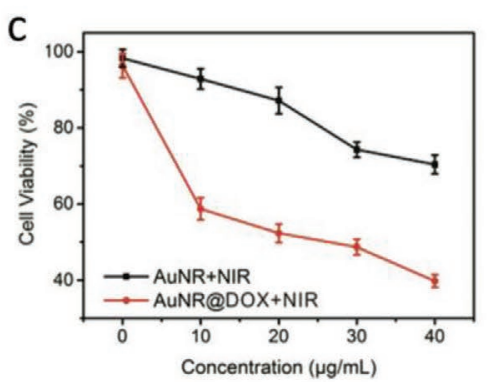

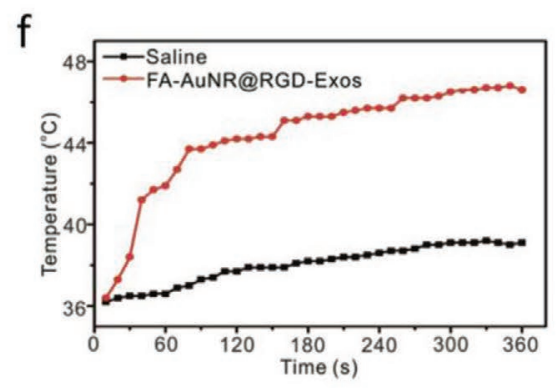

Figure 10. Photoresponsive FA-AuNR@RGD-Exos for targeted PTT. a) Schematic illustration of the design of FA-AuNR@RGD-DOX-Exos and their antitumor effect under NIR irradiation. b) Schematic illustration of drug release from the AuNR@Exos under NIR irradiation. c) Cytotoxic effects of the AuNRs and AuNR@DOX-Exos with NIR laser irradiation on HeLa cells. d) Overall fluorescence imaging of HeLa xenograft nude mice after the injection of FA-AuNR@RGD-DOX-Exos. In vivo NIR fluorescence images were taken before injection and at 1, 6, 12, 24, and 48 h post-injection. e) Thermal imaging and f) photothermal heating curves of FA-AuNR@ RGD-DOX-Exos in mouse tumors under NIR irradiation. Abbreviations: AuNR, gold nanorods; DOX, doxorubicin; DSPE, 1, 2-distearoyl-sn-glycero-3-phosphoethanolamine; Exos, exosomes; FA, folic acid; NIR, near infrared; PEG, polyethylene glycol; RGD, arginyl-glycyl-aspartic acid. Reproduced with permission. ${ }^{[138]}$ Copyright 2018, Wiley-VCH.

In addition to EVs from genetically engineered cells, researchers have used EVs secreted by tumor cells after irradiation for cancer immunotherapy. A recent study shows that irradiated tumor cell-derived MPs (RT-MPs) induce immunogenic death through ferroptosis. RT-MPs re-polarize M2 to M1 TAMs to exert antitumor response. ${ }^{[149]}$ Another study also shows that irradiated tumor cells have enhanced immunogenicity by upregulating the expression of tumor-associated antigen and damage associated molecular patterns in EVs. ${ }^{[150]}$ These results suggest that EVs from artificially manipulated tumor cells may elicit stronger immune response and better immunotherapy effects.

\section{Conclusions}

EVs have shown great value in drug delivery due to their high biocompatibility and strong bioactivity. In the past decade, great efforts have been made to the studies of EV biology, isolation and detection, therapeutic use, modification, and engineering. ${ }^{[17,151]}$
Compared with traditional nanovectors, EVs are natural nanomaterials that can be used as efficient and safe delivery vehicles. As a result of the unique membrane-enclosed structure and surface protein expression pattern, EVs are able to protect their cargos 43 from degradation and escape from the clearance by host immune 44 system. In addition, the inherent targeting ability from their 45 parental cells endows EVs with the potential of targeted therapy. 46 Compared with free formulation of drugs, EV-mediated delivery 47 shows enhanced capacity to penetrate through tumor blood ves- 48 sels and across biological barriers to accumulate at tumor sites, 49 which greatly improve their therapeutic efficacy. ${ }^{[14,39]}$ Moreover, 50 the biocompatible properties of EVs also reduce the risk of sys- 51 temic toxicity that is commonly observed in other nanomaterials. 52

As a result of these advantages, therapeutic applications of 53 EVs as drug delivery NVs have been explored in numerous 54 pre-clinical studies and several clinical trials. The delivery of 55 therapeutic RNAs and proteins, drugs, and NPs by EVs has 56 been widely reported and shown promising results in various 57 cancers. ${ }^{[152]}$ More importantly, researchers have used many 58 advanced nanotechnologies to modify, engineer, and design 59 


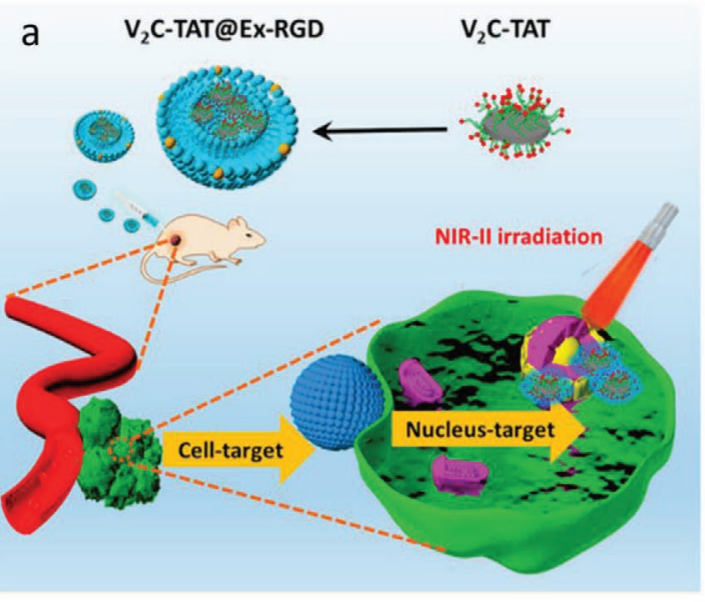

b

d

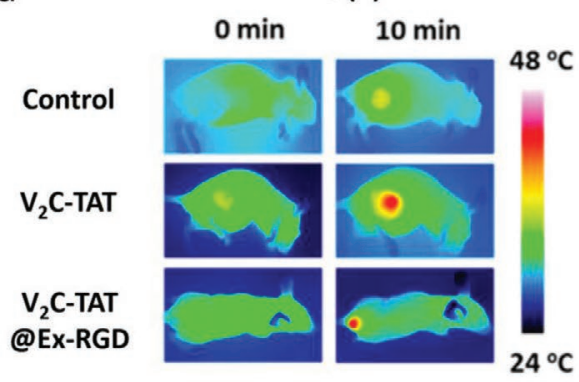

\section{$\mathrm{V}_{2} \mathrm{C}$-TAT @Ex-RGD}

C

Control

$V_{2}$ C-TAT

$V_{2}$ C-TAT @Ex-RGD

e

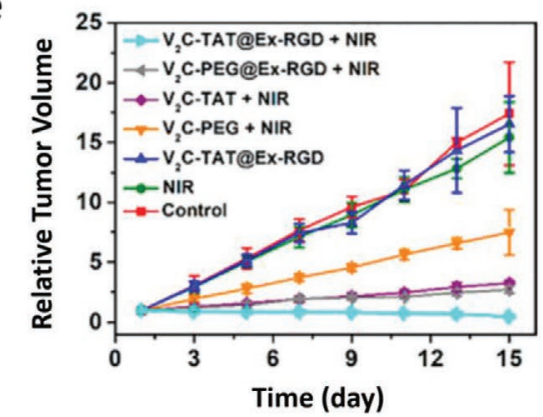

1

Figure 11. V 2 C-TAT@Ex-RGD for low-temperature nucleus-targeted PTT in the near-infrared-II region. a) Schematic illustration of the design and dualtargeting ability of $\mathrm{V}_{2} \mathrm{C}$-TAT@Ex-RGD. b) T1-weighted magnetic resonance images of mice $24 \mathrm{~h}$ after intravenous injection of PBS and $\mathrm{V}_{2} \mathrm{C}-\mathrm{TAT} @ \mathrm{Ex}-\mathrm{RGD}$. c) Photoacoustic images of mice $12 \mathrm{~h}$ after intravenous injection of PBS, $\mathrm{V}_{2} \mathrm{C}$-TAT, and $\mathrm{V}_{2} \mathrm{C}$-TAT@Ex-RGD. d) Infrared thermal images at the tumor sites of the MCF-7 tumor-bearing mice under laser irradiation after different treatments. e) Time-dependent relative tumor growth curves of the MCF-7 tumor-bearing mice after different treatments. Abbreviations: Ex, exosomes; NIR, near infrared; PEG, polyethylene glycol; RGD, arginyl-glycyl-aspartic acid; $V_{2}$ C-TAT, vanadium carbide quantum dots modified with TAT peptides. Reproduced with permission. ${ }^{[140]}$ Copyright 2019, American Chemical Society.

EVs to improve their loading efficiency, targeting ability, and therapeutic efficacy. ${ }^{[153]}$ In addition, many research groups have developed new methodologies to increase the yield of EVs and to fabricate large scale of EVs for clinical use. The procedure for generating clinical-grade and GMP standard EVs has also been reported. Moreover, bio-inspired and bio-mimetic EV-like NVs have been constructed and used as an alternative to natural EVs for improved drug delivery efficiency and therapeutic effect. Therefore, modified, engineered, and designer EVs represent a new development trend of this field, which is of great clinical value if optimized and integrated properly (Figure 12).

Although great progress has been made, there are also several challenges that may hinder therapeutic applications of engineered EVs. ${ }^{[154]}$ The first challenge is massive and stable production of engineered EVs for clinical use. The traditional approaches such as ultracentrifugation have limitations such as poor reproducibility, time-consuming procedures, and low production yield. Large-scale manufacturing of therapeutic engineered EVs may be achieved by increasing the production of EVs using bioreactor and developing streamlined purification protocol via microfluidic devices. For example, Waston et al. have developed a hollow-fiber bioreactor for efficient production of bioactive EVs with more than 40-fold yields compared to conventional cell culture. ${ }^{[155]}$ Alternatively, the generation of cell-derived NVs may also provide a scalable, efficient, and simple production of EVs. ${ }^{[144,156]}$ In addition, the standardization of engineered EV preparations to ensure quality control is also important for their use in therapy. Furthermore, the question of which type of cells is mostly suitable for the generation of engineered EVs still warrants further investigation.

The second challenge needs to be addressed is to improve the efficiency of cargo loading when engineering EVs, which may determine the application potential of these novel nanovehicles in cancer therapy. ${ }^{[15,153]}$ To solve this problem, the optimized methods for drug encapsulation into EVs should be carefully developed to achieve maximum efficiency and reduce the need of using large amounts of EVs. For example, hybrid EVs and EV membrane-camouflaged NVs could combine the advantages of natural EVs with that of synthesized NPs, thus enhancing drug loading efficiency and therapeutic efficacy. In addition, elucidating the factors that critically determine drug loading efficiency is of fundamental importance in therapeutic applications, including the kinetic of release, biodistribution, clearance, the events following the contact with target cells, and the intracellular fate after internalization. ${ }^{[157]}$ Further understanding of EV biology is required to support optimal utility.

Third, considering that EVs harbor a discrete set of proteins and functional immune molecules, the application of engineered 


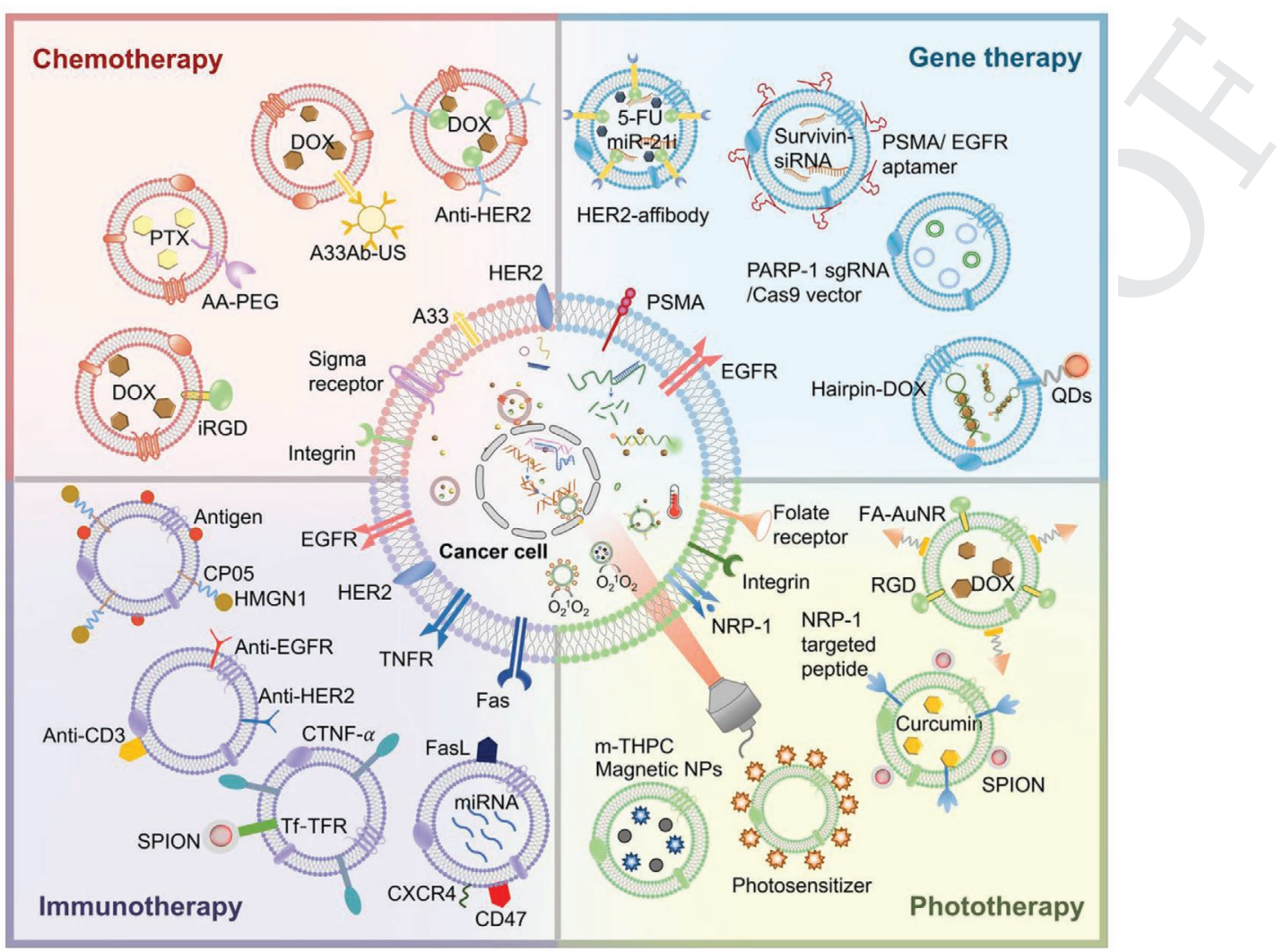

Figure 12. Engineered EVs for improved cancer therapy. Engineered EVs can serve as drug delivery systems for targeted chemotherapy, gene therapy, phototherapy, PDT, and immunotherapy. The modified EVs have better targeting ability, improved therapeutic effect, and higher safety compared to unmodified ones. Abbreviations: 5-FU, fluorouracil; A33Ab, A33 antibody; AA-PEG, aminoethylanisamide-polyethylene glycol; AuNR, gold nanorods; CTNF- $\alpha$, fusion proteins of cell-penetrating peptides and TNF- $\alpha$; CXCR4, C-X-C chemokine receptor type 4; FA, folic acid; FasL: Fas ligand; HMGN1, high mobility group nucleosome binding domain protein 1; NPs, nanoparticles; NRP-1, Neuropilin-l; PARP, poly (ADP-ribose) polymerase; PSMA, prostate specific membrane antigen; PTX: paclitaxel; QDs, quantum dots; RGD, arginyl-glycyl-aspartic acid; sgRNA, small guide RNA; SPION, superparamagnetic iron oxide nanoparticle; Tf, transferrin; TFR, transferrin receptor; THPC, m-tetra hydroxyphenyl chlorin.

EVs may trigger potent reactions by host immune systems to a certain extent, resulting in rapid elimination of EV-based drug delivery systems. ${ }^{[158]}$ Therefore, the comprehensive preclinical examinations, including pharmacokinetics, pharmacodynamics, and toxicity profiles, should be addressed in order to prevent potential side effects. Developing therapeutic approaches by using bio-inspired and bio-mimetic EVs may represent a new direction. ${ }^{[17]}$ The discoveries of efficient homing ligands or peptides for different tissues is also helpful to increase the targeting ability of EVs. ${ }^{[159]}$ Moreover, the processes of modification and engineering may change the contents and compositions of EVs, which may compromise their biological functionality and induce immunogenicity. Therefore, it is necessary to develop new methods that engineer EVs with no adverse impact on their biological properties and broaden their therapeutic applications. Finally, previous studies have shown that EVs from distinct sources and distinct EV subtypes have different organ biodistribution patterns and biological functions. ${ }^{[160]}$ For example, CD47-high EVs that deliver Kras ${ }^{\text {G12D }}$ siRNA or shRNA efficiently suppress orthotopic human pancreatic cancer growth, while this effect is compromised by pre-incubation of EVs with antiCD47 neutralizing antibodies. ${ }^{[92]}$ CD54 protein (also known as ICAM1) is involved in the enhanced tumor accumulation of tumor EVs and blockade of CD54 by antibodies significantly reducing drug accumulation in tumor tissues. ${ }^{[14]}$ These findings indicate that distinct EV subtypes may have different delivery efficiency, targeting ability, and therapeutic outcome. The selection of EV subtypes that display favorable targeting properties may provide new insights into therapeutic applications of EVs.

Overall, the recent studies of using engineered EVs to treat dif- 43 ferent cancers in pre-clinical studies and clinical trials, either alone 44 or in combination with other therapeutics, are summarized in this 45 review. In general, the concept of utilizing engineered EVs as new 46 regimens for cancer therapy is attractive and promising. We expect 47 that the resolution of these key issues would lead to engineered 48 EVs as a novel strategy for cancer therapy in the near future.

\section{Acknowledgements}

X.Z., H.Z., and J.G. contributed equally to this work. The authors thank the members of Zhang lab for helpful discussion and paper preparation. This work was supported by the National Natural Science Foundation of China (81972310, 81672416), Distinguished Young Scholar Project of Jiangsu Province (2020), Major Natural Science Research Project for Universities in Jiangsu Province (18KJA320001), Key Laboratory of Molecular Diagnostics and Precision Medicine for Surgical 
Oncology in Gansu Province (2019GSZDSYS01), Priority Academic Program Development of Jiangsu Higher Education Institutions (PAPD), Distinguished Clinical Investigator Grant of Jiangsu Province (JSTP201701), Jiangsu Provincial Key Research and Development Programme (Grant No. BE2018690). H.A.S. acknowledges financial support from the HiLIFE Research Funds, the Sigrid Jusélius Foundation, and the Academy of Finland (decision no. 317042).

\section{Conflict of Interest}

The authors declare no conflict of interest.

\section{Keywords}

bio-inspiration, cancer therapy, extracellular vesicles, nanomaterial, nanotechnology

Received: August 22, 2020 Revised: October 22, 2020 Published online:

[1] R. Kalluri, V. S. LeBleu, Science 2020, 367, eaau6977.

[2] a) S. L. N. Maas, X. O. Breakefield, A. M. Weaver, Trends Cell Biol. 2017, 27, 172; b) M. Mathieu, L. Martin-Jaular, G. Lavieu, C. Thery, Nat. Cell Biol. 2019, 21, 9.

[3] M. Tkach, C. Thery, Cell 2016, 164, 1226.

[4] W. Liao, Y. Du, C. Zhang, F. Pan, Y. Yao, T. Zhang, Q. Peng, Acta Biomater. 2019, 86, 1.

[5] L. Barile, G. Vassalli, Pharmacol. Ther. 2017, 174, 63.

[6] I. L. Colao, R. Corteling, D. Bracewell, I. Wall, Trends Mol. Med. 2018, 24, 242.

[7] C. Liu, C. Su, Theranostics 2019, 9, 1015.

[8] C. He, S. Zheng, Y. Luo, B. Wang, Theranostics 2018, 8, 237.

[9] O. M. Elsharkasy, J. Z. Nordin, D. W. Hagey, O. G. de Jong, R. M. Schiffelers, S. E. L. Andaloussi, P. Vader, Adv. Drug Delivery Rev. 2020.

[10] S. E. Andaloussi, I. Mager, X. O. Breakefield, M. J. Wood, Nat. Rev. Drug Discovery 2013, 12, 347.

[11] J. P. Armstrong, M. N. Holme, M. M. Stevens, ACS Nano 2017, 11, 69.

[12] C. P. Lai, O. Mardini, M. Ericsson, S. Prabhakar, C. Maguire, J. W. Chen, B. A. Tannous, X. O. Breakefield, ACS Nano 2014, 8, 483.

[13] P. Vader, E. A. Mol, G. Pasterkamp, R. M. Schiffelers, Adv. Drug Delivery Rev. 2016, 106, 148.

[14] T. Yong, D. Wang, X. Li, Y. Yan, J. Hu, L. Gan, X. Yang, J. Controlled Release 2020, 322, 555.

[15] B. Yang, Y. Chen, J. Shi, Adv. Mater. 2019, 31, 1802896.

[16] P. H. L. Tran, D. Xiang, T. T. D. Tran, W. Yin, Y. Zhang, L. Kong, K. Chen, M. Sun, Y. Li, Y. Hou, Y. Zhu, W. Duan, Adv. Mater. 2020, 32, 1904040.

[17] M. Lu, Y. Huang, Biomaterials 2020, 242, 119925.

[18] a) G. van Niel, G. D’Angelo, G. Raposo, Nat. Rev. Mol. Cell Biol. 2018, 19, 213; b) M. L. Merchant, I. M. Rood, J. K. J. Deegens, J. B. Klein, Nat. Rev. Nephrol. 2017, 13, 731.

[19] C. Villarroya-Beltri, C. Gutierrez-Vazquez, F. Sanchez-Cabo, D. Perez-Hernandez, J. Vazquez, N. Martin-Cofreces, D. J. Martinez-Herrera, A. Pascual-Montano, M. Mittelbrunn, F. Sanchez-Madrid, Nat. Commun. 2013, 4, 2980.

[20] D. Koppers-Lalic, M. Hackenberg, I. V. Bijnsdorp, M. A. J. van Eijndhoven, P. Sadek, D. Sie, N. Zini, J. M. Middeldorp, B. Ylstra, R. X. de Menezes, T. Wurdinger, G. A. Meijer, D. M. Pegtel, Cell Rep. 2014, 8, 1649.
[21] A. J. McKenzie, D. Hoshino, N. H. Hong, D. J. Cha, J. L. Franklin, 1 R. J. Coffey, J. G. Patton, A. M. Weaver, Cell Rep. 2016, 15, 978.

[22] K. Mukherjee, B. Ghoshal, S. Ghosh, Y. Chakrabarty, S. Shwetha, S. Das, S. N. Bhattacharyya, EMBO Rep. 2016, 17, 1184.

[23] J. W. Clancy, Y. Zhang, C. Sheehan, C. D'Souza-Schorey, Nat. Cell Biol. 2019, 21, 856.

[24] L. Zitvogel, A. Regnault, A. Lozier, J. Wolfers, C. Flament, D. Tenza, P. Ricciardi-Castagnoli, G. Raposo, S. Amigorena, Nat. Med. 1998, 4, 594.

[25] J. M. Pitt, F. Andre, S. Amigorena, J. C. Soria, A. Eggermont, G. Kroemer, L. Zitvogel, J. Clin. Invest. 2016, 126, 1224.

[26] F. Andre, N. E. Schartz, M. Movassagh, C. Flament, P. Pautier, P. Morice, C. Pomel, C. Lhomme, B. Escudier, T. Le Chevalier, T. Tursz, S. Amigorena, G. Raposo, E. Angevin, L. Zitvogel, Lancet 2002, 360, 295.

[27] M. Samuel, S. Gabrielsson, J. Intern. Med. 2019.

[28] S. Munich, A. Sobo-Vujanovic, W. J. Buchser, D. Beer-Stolz, N. L. Vujanovic, Oncolmmunology 2012, 1, 1074.

[29] a) B. Escudier, T. Dorval, N. Chaput, F. Andre, M. P. Caby, S. Novault, C. Flament, C. Leboulaire, C. Borg, S. Amigorena, C. Boccaccio, C. Bonnerot, O. Dhellin, M. Movassagh, S. Piperno, C. Robert, V. Serra, N. Valente, J. B. Le Pecq, A. Spatz, O. Lantz, T. Tursz, E. Angevin, L. Zitvogel, J. Transl. Med. 2005, 3, 10; b) B. Besse, M. Charrier, V. Lapierre, E. Dansin, O. Lantz, D. Planchard, T. Le Chevalier, A. Livartoski, F. Barlesi, A. Laplanche, S. Ploix, N. Vimond, I. Peguillet, C. Thery, L. Lacroix, I. Zoernig, K. Dhodapkar, M. Dhodapkar, S. Viaud, J. C. Soria, K. S. Reiners, E. Pogge von Strandmann, F. Vely, S. Rusakiewicz, A. Eggermont, J. M. Pitt, L. Zitvogel, N. Chaput, Oncolmmunology 2016, 5, e1071008.

[30] J. Wolfers, A. Lozier, G. Raposo, A. Regnault, C. Thery, C. Masurier, C. Flament, S. Pouzieux, F. Faure, T. Tursz, E. Angevin, S. Amigorena, L. Zitvogel, Nat. Med. 2001, 7, 297.

[31] S. Dai, D. Wei, Z. Wu, X. Zhou, X. Wei, H. Huang, G. Li, Mol. Ther. 2008, 16, 782.

[32] X. Zhang, X. Yuan, H. Shi, L. Wu, H. Qian, W. Xu, J. Hematol. Oncol. 2015, 8, 83.

[33] L. Lugini, S. Cecchetti, V. Huber, F. Luciani, G. Macchia, F. Spadaro, L. Paris, L. Abalsamo, M. Colone, A. Molinari, F. Podo, L. Rivoltini, C. Ramoni, S. Fais, J. Immunol. 2012, 189, 2833.

[34] L. Zhu, S. Kalimuthu, P. Gangadaran, J. M. Oh, H. W. Lee, S. H. Baek, S. Y. Jeong, S. W. Lee, J. Lee, B. C. Ahn, Theranostics 2017, 7, 2732.

[35] A. Shoae-Hassani, A. A. Hamidieh, M. Behfar, R. Mohseni, S. A. Mortazavi-Tabatabaei, S. Asgharzadeh, J. Immunother. 2017, 40, 265.

[36] a) P. Neviani, P. M. Wise, M. Murtadha, C. W. Liu, C. H. Wu, A. Y. Jong, R. C. Seeger, M. Fabbri, Cancer Res. 2019, 79, 1151; b) H. Sun, K. Shi, K. Qi, H. Kong, J. Zhang, S. Dai, W. Ye, T. Deng, Q. He, M. Zhou, Front. Immunol. 2019, 10, 2819.

[37] L. Zhu, S. Kalimuthu, J. M. Oh, P. Gangadaran, S. H. Baek, S. Y. Jeong, S. W. Lee, J. Lee, B. C. Ahn, Biomaterials 2019, 190-191, 38

[38] L. Cheng, Y. Wang, L. Huang, Mol. Ther. 2017, 25, 1665.

[39] P. Wang, H. Wang, Q. Huang, C. Peng, L. Yao, H. Chen, Z. Qiu, Y. Wu, L. Wang, W. Chen, Theranostics 2019, 9, 1714.

[40] Y. W. Choo, M. Kang, H. Y. Kim, J. Han, S. Kang, J. R. Lee, G. J. Jeong, S. P. Kwon, S. Y. Song, S. Go, M. Jung, J. Hong, B. S. Kim, ACS Nano 2018, 12, 8977.

[41] Z. Fan, K. Xiao, J. Lin, Y. Liao, X. Huang, Small 2019, 15, 1903761.

[42] H. Cai, X. Yang, Y. Gao, Z. Xu, B. Yu, T. Xu, X. Li, W. Xu, X. Wang, L. Hua, Mol. Ther.-Nucleic Acids 2019, 18, 787.

[43] H. Xu, G. Zhao, Y. Zhang, H. Jiang, W. Wang, D. Zhao, J. Hong, H. Yu, L. Qi, Stem Cell Res. Ther. 2019, 10, 381.

[44] Y. Che, X. Shi, Y. Shi, X. Jiang, Q. Ai, Y. Shi, F. Gong, W. Jiang, Mol. Ther.-Nucleic Acids 2019, 18, 232.

[45] Y. Liu, B. Song, Y. Wei, F. Chen, Y. Chi, H. Fan, N. Liu, Z. Li, Z. Han, F. Ma, Cytotherapy 2018, 20, 181. 
[46] V. de Araujo Farias, F. O'Valle, S. Serrano-Saenz, P. Anderson, E. Andres, J. Lopez-Penalver, I. Tovar, A. Nieto, A. Santos, F. Martin, J. Exposito, F. J. Oliver, J. M. R. de Almodovar, Mol. Cancer 2018, 17, 122.

[47] F. Vakhshiteh, F. Atyabi, S. N. Ostad, Int. J. Nanomed. 2019, 14, 2847.

[48] a) W. Jo, J. Kim, J. Yoon, D. Jeong, S. Cho, H. Jeong, Y. J. Yoon, S. C. Kim, Y. S. Cho, J. Park, Nanoscale 2014, 6, 12056; b) J. Phan, P. Kumar, D. Hao, K. Gao, D. Farmer, A. Wang, J. Extracell. Vesicles 2018, 7, 1522236.

[49] T. Smyth, M. Kullberg, N. Malik, P. Smith-Jones, M. W. Graner, T. J. Anchordoquy, J. Controlled Release 2015, 199, 145.

[50] S. M. Kim, Y. Yang, S. J. Oh, Y. Hong, M. Seo, M. Jang, J. Controlled Release 2017, 266, 8.

[51] K. Yaddanapudi, S. Meng, A. G. Whitt, N. Al Rayyan, J. Richie, A. Tu, J. W. Eaton, C. Li, Oncolmmunology 2019, 8, 1561119.

[52] J. L. Munoz, S. A. Bliss, S. J. Greco, S. H. Ramkissoon, K. L. Ligon, P. Rameshwar, Mol. Ther.-Nucleic Acids 2013, 2, e126.

[53] W. Fu, C. Lei, S. Liu, Y. Cui, C. Wang, K. Qian, T. Li, Y. Shen, X. Fan, F. Lin, M. Ding, M. Pan, X. Ye, Y. Yang, S. Hu, Nat. Commun. 2019, $10,4355$.

[54] H. Qi, C. Liu, L. Long, Y. Ren, S. Zhang, X. Chang, X. Qian, H. Jia, J. Zhao, J. Sun, X. Hou, X. Yuan, C. Kang, ACS Nano 2016, 10, 3323.

[55] S. Pan, L. Pei, A. Zhang, Y. Zhang, C. Zhang, M. Huang, Z. Huang, B. Liu, L. Wang, L. Ma, Q. Zhang, D. Cui, Biomaterials 2020, 230, 119606.

[56] A. K. Agrawal, F. Aqil, J. Jeyabalan, W. A. Spencer, J. Beck, B. W. Gachuki, S. S. Alhakeem, K. Oben, R. Munagala, S. Bondada, R. C. Gupta, Nanomedicine 2017, 13, 1627.

[57] V. Agrahari, V. Agrahari, P. A. Burnouf, C. H. Chew, T. Burnouf, Trends Biotechnol. 2019, 37, 707.

[58] L. Pascucci, V. Cocce, A. Bonomi, D. Ami, P. Ceccarelli, E. Ciusani, L. Vigano, A. Locatelli, F. Sisto, S. M. Doglia, E. Parati, M. E. Bernardo, M. Muraca, G. Alessandri, G. Bondiolotti, A. Pessina, J. Controlled Release 2014, 192, 262.

[59] a) K. Ridder, A. Sevko, J. Heide, M. Dams, A. K. Rupp, J. Macas, J. Starmann, M. Tjwa, K. H. Plate, H. Sultmann, P. Altevogt, V. Umansky, S. Momma, Oncolmmunology 2015, 4, e1008371; b) B. Wang, K. Yao, B. M. Huuskes, H. H. Shen, J. Zhuang, C. Godson, E. P. Brennan, J. L. Wilkinson-Berka, A. F. Wise, S. D. Ricardo, Mol. Ther. 2016, 24, 1290; c) H. Zhang, Y. Wang, M. Bai, J. Wang, K. Zhu, R. Liu, S. Ge, J. Li, T. Ning, T. Deng, Q. Fan, H. Li, W. Sun, G. Ying, Y. Ba, Cancer Sci. 2018, 109, 629.

[60] G. Fuhrmann, R. Chandrawati, P. A. Parmar, T. J. Keane, S. A. Maynard, S. Bertazzo, M. M. Stevens, Adv. Mater. 2018, 30, 1706616.

[61] G. Fuhrmann, A. Serio, M. Mazo, R. Nair, M. M. Stevens, J. Controlled Release 2015, 205, 35.

[62] G. Liang, S. Kan, Y. Zhu, S. Feng, W. Feng, S. Gao, Int. J. Nanomed. 2018, 13, 585.

[63] a) G. Wu, J. Zhang, Q. Zhao, W. Zhuang, J. Ding, C. Zhang, H. Gao, D. W. Pang, K. Pu, H. Y. Xie, Angew. Chem., Int. Ed. Engl. 2020, 59, 4068; b) L. Alvarez-Erviti, Y. Seow, H. Yin, C. Betts, S. Lakhal, M. J. Wood, Nat. Biotechnol. 2011, 29, 341.

[64] S. A. A. Kooijmans, S. Stremersch, K. Braeckmans, S. C. de Smedt, A. Hendrix, M. J. A. Wood, R. M. Schiffelers, K. Raemdonck, P. Vader, J. Controlled Release 2013, 172, 229.

[65] M. J. Haney, N. L. Klyachko, Y. Zhao, R. Gupta, E. G. Plotnikova, Z. He, T. Patel, A. Piroyan, M. Sokolsky, A. V. Kabanov, E. V. Batrakova, J. Controlled Release 2015, 207, 18.

[66] M. S. Kim, M. J. Haney, Y. Zhao, V. Mahajan, I. Deygen, N. L. Klyachko, E. Inskoe, A. Piroyan, M. Sokolsky, O. Okolie, S. D. Hingtgen, A. V. Kabanov, E. V. Batrakova, Nanomedicine 2016, 12, 655.

[67] X. Luan, K. Sansanaphongpricha, I. Myers, H. Chen, H. Yuan, D. Sun, Acta Pharmacol. Sin. 2017, 38, 754.

[68] G. Jia, Y. Han, Y. An, Y. Ding, C. He, X. Wang, Q. Tang, Biomaterials 2018, 178, 302.
[69] T. Tian, H. X. Zhang, C. P. He, S. Fan, Y. L. Zhu, C. Qi, N. P. Huang, 1 Z. D. Xiao, Z. H. Lu, B. A. Tannous, J. Gao, Biomaterials 2018, 150, 2 137.

[70] F. Pi, D. W. Binzel, T. J. Lee, Z. Li, M. Sun, P. Rychahou, H. Li, 4 F. Haque, S. Wang, C. M. Croce, B. Guo, B. M. Evers, P. Guo, Nat. Nanotechnol. 2018, 13, 82.

[71] S. A. Kooijmans, C. G. Aleza, S. R. Roffler, W. W. van Solinge, 6 P. Vader, R. M. Schiffelers, J. Extracell. Vesicles 2016, 5, 31053.

[72] a) X. Gao, N. Ran, X. Dong, B. Zuo, R. Yang, Q. Zhou, 8 H. M. Moulton, Y. Seow, H. Yin, Sci. Transl. Med. 2018, 10, 9 eaat0195; b) X. Wang, Y. Chen, Z. Zhao, Q. Meng, Y. Yu, J. Sun, 10 Z. Yang, Y. Chen, J. Li, T. Ma, H. Liu, Z. Li, J. Yang, Z. Shen, J. Am. 11 Heart Assoc. 2018, 7, e008737.

[73] N. Yim, S. W. Ryu, K. Choi, K. R. Lee, S. Lee, H. Choi, J. Kim, M. R. Shaker, W. Sun, J. H. Park, D. Kim, W. D. Heo, C. Choi, Nat. Commun. 2016, 7, 12277.

[74] J. Wang, W. Li, L. Zhang, L. Ban, P. Chen, W. Du, X. Feng, B. F. Liu, ACS Appl. Mater. Interfaces 2017, 9, 27441.

[75] A. J. Vazquez-Rios, A. Molina-Crespo, B. L. Bouzo, R. Lopez-Lopez, G. Moreno-Bueno, M. de la Fuente, J. Nanobiotechnol. 2019, 17, 85.

[76] W. Jo, D. Jeong, J. Kim, S. Cho, S. C. Jang, C. Han, J. Y. Kang, Y. S. Gho, J. Park, Lab Chip 2014, 14, 1261.

[77] S. C. Jang, O. Y. Kim, C. M. Yoon, D. S. Choi, T. Y. Roh, J. Park, 21 J. Nilsson, J. Lotvall, Y. K. Kim, Y. S. Gho, ACS Nano 2013, 7, 7698.

[78] J. Yoon, W. Jo, D. Jeong, J. Kim, H. Jeong, J. Park, Biomaterials 2015, 59, 12.

[79] Y. Lin, J. Wu, W. Gu, Y. Huang, Z. Tong, L. Huang, J. Tan, Adv. Sci. 2018, 5, 1700611

[80] K. L. Zhang, Y. J. Wang, J. Sun, J. Zhou, C. Xing, G. Huang, J. Li, H. Yang, Chem. Sci. 2019, 10, 1555.

[81] G. Cheng, W. Li, L. Ha, X. Han, S. Hao, Y. Wan, Z. Wang, F. Dong, X. Zou, Y. Mao, S. Y. Zheng, J. Am. Chem. Soc. 2018, 140, 7282.

[82] R. J. C. Bose, S. Uday Kumar, Y. Zeng, R. Afjei, E. Robinson, K. Lau, 30 A. Bermudez, F. Habte, S. J. Pitteri, R. Sinclair, J. K. Willmann, 31 T. F. Massoud, S. S. Gambhir, R. Paulmurugan, ACS Nano 2018, 32 12, 10817.

[83] C. Liu, W. Zhang, Y. Li, J. Chang, F. Tian, F. Zhao, Y. Ma, J. Sun, Nano Lett. 2019, 19, 7836.

[84] P. Gee, M. S. Y. Lung, Y. Okuzaki, N. Sasakawa, T. Iguchi, Y. Makita, H. Hozumi, Y. Miura, L. F. Yang, M. Iwasaki, X. H. Wang, M. A. Waller, N. Shirai, Y. O. Abe, Y. Fujita, K. Watanabe, A. Kagita, K. A. Iwabuchi, M. Yasuda, H. Xu, T. Noda, J. Komano, H. Sakurai, N. Inukai, A. Hotta, Nat. Commun. 2020, 11, 1334.

[85] A. Mizrak, M. F. Bolukbasi, G. B. Ozdener, G. J. Brenner, S. Madlener, E. P. Erkan, T. Strobel, X. O. Breakefield, O. Saydam, Mol. Ther. 2013, 21, 101.

[86] E. P. Erkan, D. Senfter, S. Madlener, G. Jungwirth, T. Strobel, N. Saydam, O. Saydam, Cancer Gene Ther. 2017, 24, 38.

[87] M. Kanada, B. D. Kim, J. W. Hardy, J. A. Ronald, M. H. Bachmann, M. P. Bernard, G. I. Perez, A. A. Zarea, T. J. Ge, A. Withrow, S. A. Ibrahim, V. Toomajian, S. S. Gambhir, R. Paulmurugan, C. H. Contag, Mol. Cancer Ther. 2019, 18, 2331.

[88] U. Altanerova, J. Jakubechova, K. Benejova, P. Priscakova, M. Pesta, P. Pitule, O. Topolcan, J. Kausitz, M. Zduriencikova, V. Repiska, C. Altaner, Int. J. Cancer 2019, 144, 897.

[89] Z. Yang, J. Shi, J. Xie, Y. Wang, J. Sun, T. Liu, Y. Zhao, X. Zhao, X. Wang, Y. Ma, V. Malkoc, C. Chiang, W. Deng, Y. Chen, Y. Fu, K. J. Kwak, Y. Fan, C. Kang, C. Yin, J. Rhee, P. Bertani, J. Otero, W. Lu, K. Yun, A. S. Lee, W. Jiang, L. Teng, B. Y. S. Kim, L. J. Lee, Nat. Biomed. Eng. 2020, 4, 69.

[90] R. Kojima, D. Bojar, G. Rizzi, G. C. Hamri, M. D. El-Baba, P. Saxena, S. Auslander, K. R. Tan, M. Fussenegger, Nat. Commun. 2018, 9, 1305.

[91] a) J. Wahlgren, L. K. T. De, M. Brisslert, F. Vaziri Sani, E. Telemo, P. Sunnerhagen, H. Valadi, Nucleic Acids Res. 2012, 40, e130; b) Z. Yang, J. Xie, J. Zhu, C. Kang, C. Chiang, X. Wang, X. Wang, ? .

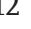

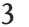
19 20 21 22 28 9

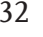
列 (7) s1 52 年 st 5 s6 57

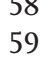

3

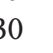
38 58 
T. Kuang, F. Chen, Z. Chen, A. Zhang, B. Yu, R. J. Lee, L. Teng, L. J. Lee, J. Controlled Release 2016, 243, 160.

[92] S. Kamerkar, V. S. LeBleu, H. Sugimoto, S. Yang, C. F. Ruivo, S. A. Melo, J. J. Lee, R. Kalluri, Nature 2017, 546, 498.

[93] Z. Zheng, Z. Li, C. Xu, B. Guo, P. Guo, J. Controlled Release 2019, $311-312,43$.

[94] T. R. Lunavat, S. C. Jang, L. Nilsson, H. T. Park, G. Repiska, C. Lasser, J. A. Nilsson, Y. S. Gho, J. Lotvall, Biomaterials 2016, 102, 231.

[95] L. Zhao, C. Gu, Y. Gan, L. Shao, H. Chen, H. Zhu, J. Controlled Release 2020, 318, 1.

[96] R. Reshke, J. A. Taylor, A. Savard, H. Guo, L. H. Rhym, P. S. Kowalski, M. T. Trung, C. Campbell, W. Little, D. G. Anderson, D. Gibbings, Nat. Biomed. Eng. 2020, 4, 52.

[97] H. Valadi, K. Ekstrom, A. Bossios, M. Sjostrand, J. J. Lee, J. O. Lotvall, Nat. Cell Biol. 2007, 9, 654.

[98] H. Zhang, J. Wang, T. Ren, Y. Huang, X. Liang, Y. Yu, W. Wang, J. Niu, W. Guo, Cancer Lett. 2020, 54.

[99] G. Lou, X. Song, F. Yang, S. Wu, J. Wang, Z. Chen, Y. Liu, J. Hematol. Oncol. 2015, 8, 122.

[100] H. Nie, X. Xie, D. Zhang, Y. Zhou, B. Li, F. Li, F. Li, Y. Cheng, H. Mei, H. Meng, L. Jia, Nanoscale 2020, 12, 877.

[101] S. Ohno, M. Takanashi, K. Sudo, S. Ueda, A. Ishikawa, N. Matsuyama, K. Fujita, T. Mizutani, T. Ohgi, T. Ochiya, N. Gotoh, M. Kuroda, Mol. Ther. 2013, 21, 185.

[102] M. Katakowski, B. Buller, X. Zheng, Y. Lu, T. Rogers, O. Osobamiro, W. Shu, F. Jiang, M. Chopp, Cancer Lett. 2013, 335, 201.

[103] F. M. Lang, A. Hossain, J. Gumin, E. N. Momin, Y. Shimizu, D. Ledbetter, T. Shahar, S. Yamashita, B. Parker Kerrigan, J. Fueyo, R. Sawaya, F. F. Lang, Neuro-Oncology 2018, 20, 380.

[104] X. Wang, H. Zhang, M. Bai, T. Ning, S. Ge, T. Deng, R. Liu, L. Zhang, G. Ying, Y. Ba, Mol. Ther. 2018, 26, 774.

[105] R. Ji, X. Zhang, H. Gu, J. Ma, X. Wen, J. Zhou, H. Qian, W. Xu, J. Qian, J. Lin, Mol. Ther.-Nucleic Acids 2019, 18, 320.

[106] Z. Li, X. Zhou, M. Wei, X. Gao, L. Zhao, R. Shi, W. Sun, Y. Duan, G. Yang, L. Yuan, Nano Lett. 2019, 19, 19.

[107] U. Sterzenbach, U. Putz, L. H. Low, J. Silke, S. S. Tan, J. Howitt, Mol. Ther. 2017, 25, 1269.

[108] J. R. Aspe, C. J. Diaz Osterman, J. M. Jutzy, S. Deshields, S. Whang N. R. Wall, J. Extracell. Vesicles 2014, 3, 23244.

[109] Y. Tian, S. Li, J. Song, T. Ji, M. Zhu, G. J. Anderson, J. Wei, G. Nie, Biomaterials 2014, 35, 2383.

[110] C. Zhao, D. J. Busch, C. P. Vershel, J. C. Stachowiak, Small 2016, 12, 3837.

[111] M. S. Kim, M. J. Haney, Y. Zhao, D. Yuan, I. Deygen, N. L. Klyachko, A. V. Kabanov, E. V. Batrakova, Nanomedicine 2018, 14, 195.

[112] M. Sancho-Albero, B. Rubio-Ruiz, A. M. Perez-Lopez, V. Sebastian, P. Martin-Duque, M. Arruebo, J. Santamaria, A. Unciti-Broceta, Nat. Catal. 2019, 2, 864.

[113] Z. Belhadj, B. He, H. Deng, S. Song, H. Zhang, X. Wang, W. Dai, Q. Zhang, J. Extracell. Vesicles 2020, 9, 1806444.

[114] a) H. Y. Kim, H. Kumar, M. J. Jo, J. Kim, J. K. Yoon, J. R. Lee, M. Kang, Y. W. Choo, S. Y. Song, S. P. Kwon, T. Hyeon, I. B. Han, B. S. Kim, Nano Lett. 2018, 18, 4965; b) M. Sancho-Albero, M. D. M. Encabo-Berzosa, M. Beltran-Visiedo, L. Fernandez-Messina, V. Sebastian, F. Sanchez-Madrid, M. Arruebo, J. Santamaria, P. Martin-Duque, Nanoscale 2019, 11, 18825.

[115] A. K. A. Silva, J. Kolosnjaj-Tabi, S. Bonneau, I. Marangon, N. Boggetto, K. Aubertin, O. Clément, M. F. Bureau, N. Luciani, F. Gazeau, ACS Nano 2013, 7, 4954.

[116] A. K. Silva, N. Luciani, F. Gazeau, K. Aubertin, S. Bonneau, C. Chauvierre, D. Letourneur, C. Wilhelm, Nanomedicine 2015, 11, 645.

[117] Y. Liu, L. Bai, K. Guo, Y. Jia, K. Zhang, Q. Liu, P. Wang, X. Wang, Theranostics 2019, 9, 5261.

[118] K. Tang, Y. Zhang, H. Zhang, P. Xu, J. Liu, J. Ma, M. Lv, D. Li, F. Katirai, G. X. Shen, G. Zhang, Z. H. Feng, D. Ye, B. Huang, Nat. Commun. 2012, 3, 1282.
[119] L. Qiao, S. Hu, K. Huang, T. Su, Z. Li, A. Vandergriff, J. Cores, 1 P. U. Dinh, T. Allen, D. Shen, H. Liang, Y. Li, K. Cheng, Theranostics 2020, 10, 3474.

[120] J. Liu, Z. Ye, M. Xiang, B. Chang, J. Cui, T. Ji, L. Zhao, Q. Li, Y. Deng, L. Xu, G. Wang, L. Wang, Z. Wang, Biomaterials 2019, 223, 119475.

[121] L. Bai, Y. Liu, K. Guo, K. Zhang, Q. Liu, P. Wang, X. Wang, ACS Appl. Mater. Interfaces 2019, 11, 14576.

[122] T. Yong, X. Zhang, N. Bie, H. Zhang, X. Zhang, F. Li, A. Hakeem, J. Hu, L. Gan, H. A. Santos, X. Yang, Nat. Commun. 2019, 10, 3838.

[123] K. Wang, H. Ye, X. Zhang, X. Wang, B. Yang, C. Luo, Z. Zhao, J. Zhao, Q. Lu, H. Zhang, Q. Kan, Y. Wang, Z. He, J. Sun, Biomaterials 2020, 257, 120224.

[124] S. Rayamajhi, T. D. T. Nguyen, R. Marasini, S. Aryal, Acta Biomater. 2019, 94, 482.

[125] F. Xiong, X. Ling, X. Chen, J. Chen, J. Tan, W. Cao, L. Ge, M. Ma, J. Wu, Nano Lett. 2019, 19, 3256.

[126] M. Mendt, S. Kamerkar, H. Sugimoto, K. M. McAndrews, C. C. Wu, M. Gagea, S. Yang, E. V. R. Blanko, Q. Peng, X. Ma, J. R. Marszalek, A. Maitra, C. Yee, K. Rezvani, E. Shpall, V. S. LeBleu, R. Kalluri, J. Clin. Invest. Insight 2018, 3, e99263.

[127] W. M. Usman, T. C. Pham, Y. Y. Kwok, L. T. Vu, V. Ma, B. Peng, Y. S. Chan, L. Wei, S. M. Chin, A. Azad, A. B. He, A. Y. H. Leung, M. Yang, N. Shyh-Chang, W. C. Cho, J. Shi, M. T. N. Le, Nat. Commun. 2018, 9, 2359.

[128] Q. Zhu, X. Ling, Y. Yang, J. Zhang, Q. Li, X. Niu, G. Hu, B. Chen, H. Li, Y. Wang, Z. Deng, Adv. Sci. 2019, 6, 1801899.

[129] S. Li, Y. Wu, F. Ding, J. Yang, J. Li, X. Gao, C. Zhang, J. Feng, Nanoscale 2020, 12, 10854.

[130] P. Zhang, L. Zhang, Z. Qin, S. Hua, Z. Guo, C. Chu, H. Lin, Y. Zhang, W. Li, X. Zhang, X. Chen, G. Liu, Adv. Mater. 2018, 30, 1705350.

[131] Q. Lin, M. Qu, B. Zhou, H. K. Patra, Z. Sun, Q. Luo, W. Yang, Y. Wu, Y. Zhang, L. Li, L. Deng, L. Wang, T. Gong, Q. He, L. Zhang, X. Sun, Z. Zhang, J. Controlled Release 2019, 311-312, 104.

[132] H. Cao, H. Wang, X. He, T. Tan, H. Hu, Z. Wang, J. Wang, J. Li, Z. Zhang, Y. Li, Nano Lett. 2018, 18, 4762.

[133] Y. Li, Y. Gao, C. Gong, Z. Wang, Q. Xia, F. Gu, C. Hu, L. Zhang, H. Guo, S. Gao, Nanomedicine 2018, 14, 1973.

[134] M. Zhuang, X. Chen, D. Du, J. Shi, M. Deng, Q. Long, X. Yin, Y. Wang, L. Rao, Nanoscale 2020, 12, 173.

[135] C. Wang, W. Guan, J. Peng, Y. Chen, G. Xu, H. Dou, Acta Biomater. 2020, 103, 247.

[136] G. Liang, Y. Zhu, D. J. Ali, T. Tian, H. Xu, K. Si, B. Sun, B. Chen, Z. Xiao, J. Nanobiotechnol. 2020, 18, 10.

[137] Q. Zhan, K. Yi, H. Qi, S. Li, X. Li, Q. Wang, Y. Wang, C. Liu, M. Qiu, X. Yuan, J. Zhao, X. Hou, C. Kang, Theranostics 2020, 10, 7889.

[138] J. Wang, Y. Dong, Y. Li, W. Li, K. Cheng, Y. Qian, G. Xu, X. Zhang, L. Hu, P. Chen, W. Du, X. Feng, Y.-D. Zhao, Z. Zhang, B.-F. Liu, Adv. Funct. Mater. 2018, 28, 1707360.

[139] H. Cheng, J. H. Fan, L. P. Zhao, G. L. Fan, R. R. Zheng, X. Z. Qiu, X. Y. Yu, S. Y. Li, X. Z. Zhang, Biomaterials 2019, 211, 14.

[140] Y. Cao, T. Wu, K. Zhang, X. Meng, W. Dai, D. Wang, H. Dong, $X$. Zhang, ACS Nano 2019, 13, 1499.

[141] D. Wang, Y. Yao, J. He, X. Zhong, B. Li, S. Rao, H. Yu, S. He, X. Feng, T. Xu, B. Yang, T. Yong, L. Gan, J. Hu, X. Yang, Adv. Sci. 2020, 7, 1901293.

[142] N. L. Syn, L. Wang, E. K.-H. Chow, C. T. Lim, B.-C. Goh, Trends Biotechnol. 2017, 35, 665 .

[143] S. Kim, H. J. Sohn, H. J. Lee, D. H. Sohn, S. J. Hyun, H. I. Cho, T. G. Kim, J. Immunother. 2017, 40, 83.

[144] Z. Zhao, J. McGill, P. Gamero-Kubota, M. He, Lab Chip 2019, 19, 1877.

[145] B. Zuo, H. Qi, Z. Lu, L. Chen, B. Sun, R. Yang, Y. Zhang, Z. Liu, X. Gao, A. You, L. Wu, R. Jing, Q. Zhou, H. Yin, Nat. Commun. 2020, 11, 1790.

[146] G. Wang, W. Hu, H. Chen, X. Shou, T. Ye, Y. Xu, Cancers 2019, 11, 1560.

2 
[147] Q. Cheng, X. Shi, M. Han, G. Smbatyan, H. J. Lenz, Y. Zhang, J. Am. Chem. Soc. 2018, 140, 16413.

[148] X. Shi, Q. Cheng, T. Hou, M. Han, G. Smbatyan, J. E. Lang, A. L. Epstein, H. J. Lenz, Y. Zhang, Mol. Ther. 2020, 28, 536.

[149] C. Wan, Y. Sun, Y. Tian, L. Lu, X. Dai, J. Meng, J. Huang, Q. He, B. Wu, Z. Zhang, K. Jiang, D. Hu, G. Wu, J. F. Lovell, H. Jin, K. Yang, Sci. Adv. 2020, 6, eaay9789.

[150] W. Lin, Y. Xu, X. Chen, J. Liu, Y. Weng, Q. Zhuang, F. Lin, Z. Huang, S. Wu, J. Ding, L. Chen, X. Qiu, L. Zhang, J. Wu, D. Lin, S. Qiu, Theranostics 2020, 10, 4871.

[151] D. Yang, W. Zhang, H. Zhang, F. Zhang, L. Chen, L. Ma, L. M. Larcher, S. Chen, N. Liu, Q. Zhao, P. H. L. Tran, C. Chen, R. N. Veedu, T. Wang, Theranostics 2020, 10, 3684.

[152] a) K. O'Brien, K. Breyne, S. Ughetto, L. C. Laurent, X. O. Breakefield, Nat. Rev. Mol. Cell Biol. 2020, 21, 585; b) S. Walker, S. Busatto, A. Pham, M. Tian, A. Suh, K. Carson, A. Quintero, M. Lafrence, H. Malik, M. X. Santana, J. Wolfram, Theranostics 2019, 9, 8001.

[153] W. Fan, B. Yung, P. Huang, X. Chen, Chem. Rev. 2017, 117, 13566.

[154] a) S. Fais, L. O'Driscoll, F. E. Borras, E. Buzas, G. Camussi, F. Cappello, J. Carvalho, A. Cordeiro da Silva, H. Del Portillo, S. El Andaloussi, T. Ficko Trcek, R. Furlan, A. Hendrix, I. Gursel, V. Kralj-Iglic, B. Kaeffer, M. Kosanovic, M. E. Lekka, G. Lipps, M. Logozzi, A. Marcilla, M. Sammar, A. Llorente, I. Nazarenko, C. Oliveira, G. Pocsfalvi, L. Rajendran, G. Raposo, E. Rohde, P. Siljander, G. van Niel, M. H. Vasconcelos, M. Yanez-Mo, M. L. Yliperttula, N. Zarovni, A. B. Zavec, B. Giebel, ACS Nano 2016, 10, 3886; b) B. Gyorgy, M. E. Hung, X. O. Breakefield, J. N. Leonard, Annu. Rev. Pharmacol. Toxicol. 2015, 55, 439.

[155] D. C. Watson, D. Bayik, A. Srivatsan, C. Bergamaschi, A. Valentin, G. Niu, J. Bear, M. Monninger, M. Sun, A. Morales-Kastresana, J. C. Jones, B. K. Felber, X. Chen, I. Gursel, G. N. Pavlakis, Biomaterials 2016, 105, 195.

[156] A. Y. Jong, C. H. Wu, J. Li, J. Sun, M. Fabbri, A. S. Wayne, R. C. Seeger, J. Extracell. Vesicles 2017, 6, 1294368.
[157] J. Bourquin, A. Milosevic, D. Hauser, R. Lehner, F. Blank, A. Petri-Fink, 1 B. Rothen-Rutishauser, Adv. Mater. 2018, 30, 1704307.

[158] S. Lim, J. Park, M. K. Shim, W. Um, H. Y. Yoon, J. H. Ryu, 3 D. K. Lim, K. Kim, Theranostics 2019, 9, 7906.

[159] S. Antimisiaris, S. Mourtas, A. Marazioti, Pharmaceutics 2018, 10, 218.

[160] a) D. Choi, L. Montermini, H. Jeong, S. Sharma, B. Meehan, J. Rak, ACS Nano 2019, 13, 10499; b) H. Zhang, D. Freitas, 7 H. S. Kim, K. Fabijanic, Z. Li, H. Chen, M. T. Mark, H. Molina, 8 A. B. Martin, L. Bojmar, J. Fang, S. Rampersaud, A. Hoshino, 9 I. Matei, C. M. Kenific, M. Nakajima, A. P. Mutvei, P. Sansone, 10 W. Buehring, H. Wang, J. P. Jimenez, L. Cohen-Gould, 11 N. Paknejad, M. Brendel, K. Manova-Todorova, A. Magalhaes, 12 J. A. Ferreira, H. Osorio, A. M. Silva, A. Massey, J. R. Cubillos-Ruiz, 13 G. Galletti, P. Giannakakou, A. M. Cuervo, J. Blenis, 14 R. Schwartz, M. S. Brady, H. Peinado, J. Bromberg, H. Matsui, 1 C. A. Reis, D. Lyden, Nat. Cell Biol. 2018, 20, 332; c) A. Hoshino, 15 B. Costa-Silva, T. L. Shen, G. Rodrigues, A. Hashimoto, M. Tesic Mark, H. Molina, S. Kohsaka, A. Di Giannatale, S. Ceder, S. Singh, C. Williams, N. Soplop, K. Uryu, L. Pharmer, T. King, L. Bojmar, A. E. Davies, Y. Ararso, T. Zhang, H. Zhang, J. Hernandez, 19 J. M. Weiss, V. D. Dumont-Cole, K. Kramer, L. H. Wexler, 20 A. Narendran, G. K. Schwartz, J. H. Healey, P. Sandstrom, 21 K. J. Labori, E. H. Kure, P. M. Grandgenett, M. A. Hollingsworth, 22 M. de Sousa, S. Kaur, M. Jain, K. Mallya, S. K. Batra, 23 W. R. Jarnagin, M. S. Brady, O. Fodstad, V. Muller, K. Pantel, A. J. Minn, M. J. Bissell, B. A. Garcia, Y. Kang, V. K. Rajasekhar, C. M. Ghajar, I. Matei, H. Peinado, J. Bromberg, D. Lyden, Nature 2015, 527, 329.

[161] D. Bellavia, S. Raimondo, G. Calabrese, S. Forte, M. Cristaldi, A. Patinella, L. Memeo, M. Manno, S. Raccosta, P. Diana, G. Cirrincione, G. Giavaresi, F. Monteleone, S. Fontana, G. De Leo, R. Alessandro, Theranostics 2017, 7, 1333.

[162] M. Morishita, Y. Takahashi, A. Matsumoto, M. Nishikawa, 31 Y. Takakura, Biomaterials 2016, 111, 55.

\section{2}

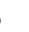
4

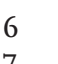

